\title{
Shedding light on the usability of ecosystem services-based decision support systems: An eye-tracking study linked to the cognitive probing approach
}

\author{
Thomas Michael Klein ${ }^{a, *}$, Thomas Drobnik ${ }^{b}$, Adrienne Grêt-Regamey ${ }^{c}$ \\ ${ }^{a}$ PLUS - Planning of Landscape and Urban Systems, ETH - Swiss Federal Institute of Technology, ETH Zurich, IRL - PLUS, \\ Stefano-Franscini-Platz 5, 8093 Zurich, +41 (0) 446339229 \\ ${ }^{b}$ PLUS - Planning of Landscape and Urban Systems, ETH - Swiss Federal Institute of Technology, drobnikt@ethz.ch \\ ' PLUS - Planning of Landscape and Urban Systems, ETH - Swiss Federal Institute of Technology, gret@ethz.ch \\ * Corresponding author. \\ E-mail address: tklein@ethz.ch (T. M. Klein)
}

Keywords: Ecosystem services information, Usability, Eye tracking, Decision-making strategy, Cognitive process

\section{Graphical abstract}

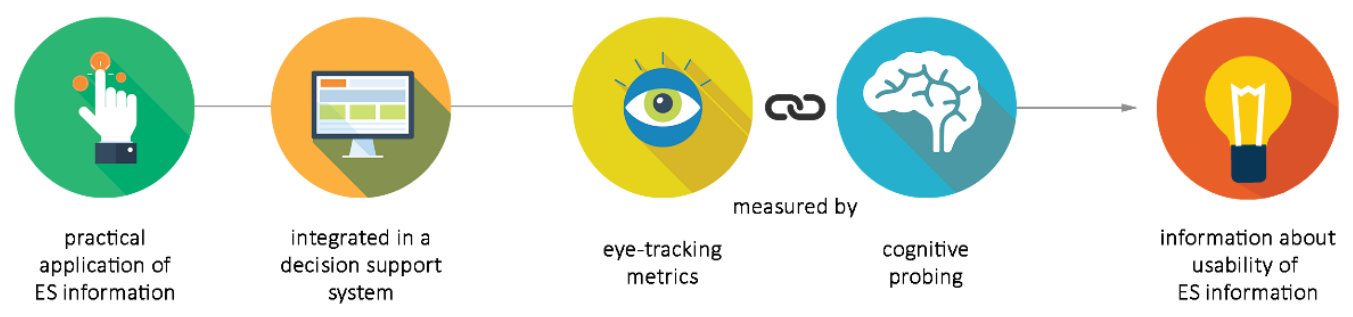

\begin{abstract}
The requirements for communicating ecosystem services (ES) information often are not considered in operationalizing ES concepts. In particular, the heterogeneous uses of ES require different functionalities and qualities for the information provided, which must be considered when processing ES data into different types of information. The relevant factors that influence the usability of ES information include the users' knowledge and cognitive ability as well as case study-specific factors. This missing knowledge can affect the transformation of the ES concept into practice, thus preventing the use of ES for further development or for transformation to sustainable management. Providing information that is relevant and useful for decision-making thus depends on understanding potential users' demands and their cognitive processes involving the information in making decisions.

In this contribution, we present the evaluation of specific design features of a prototype ES decision support system assessed in an eye-tracking experiment. The study was conducted with more than 100 participants who were split into two groups. The participants in both groups had a background in spatial planning but differed in their connection to the case study region. The tool presented various GIS-based modeled land-use scenarios driven by a new spatial planning policy recently adopted in Switzerland that lead to various impacts on ES in the region. The ES information was shown with additional land-use indicators as well as information about the landscape aesthetic in landscape visualizations. The results show that there were significant differences between the participants in the way they perceived, interpreted and used the information for ES-based decision-making tasks. We also identified critical key factors defining the types of representation of the information that influence perception and cognitive processes.

In summary, the results of the study provide design recommendations for representing ES information based on the intended use and identify critical representation features that could potentially influence the perception of ES information.
\end{abstract}

\section{Introduction}

In 2011, the European Commission (EU) adopted the EU biodiversity strategy to halt the loss of biodiversity and Ecosystem Services (ES) in the EU by 2020 (European Commission, 2012). The EU strategy targets public awareness of ES issues in addition to establishing education and communication campaigns as well as developing instruments for more effective ES management and providing information on ES. These targets are crucial elements of sound decision-making and therefore call for an improvement in and implementation of ES information in spatial planning tools and processes to provide ES-based reasoning and communication to stakeholders and the public. At the same time, the existing working group on Mapping of Ecosystems and their Services in the EU and its Member States (MESEU) has been investigating the best practices for supporting the improved implementation of ES information in policy and decision-making (MESEU, 2014). To achieve the strategy targets by 2020 , information on the ES provided at the local scale is indispensable for implementing the information in spatial planning. In terms of communication strategy, ES information can be provided in a wide range of different types and scales, but clear guidelines on which types or scales are suitable for conveying this information to various types of users is lacking (Klein et al., 2015).

A new trend is to provide the public with spatially explicit environmental information-for instance, information on provision of ES-via streamlined, easy-to-use and often web-based GIS platforms (e.g., www.ecometrica.com). Some of 
these platforms are specifically designed to provide relevant information in decision-making processes or to allow exploration of future scenarios (e.g., Wissen Hayek et al., 2015; Grêt-Regamey et al., 2013). Such platforms are also known as planning support systems or decision support systems (DSSs). In landscape and urban planning such DSS can contribute to support sound decisions that account for sustainable use of ecosystems and their providing services. The trend of such DSS emergence has been stimulated by modern information and communication technologies and policy strategies, such as worldwide access to broadband Internet (also an EU initiative; European Commission, 2015a). Furthermore, EU policy aspires to provide cross-national spatial information: For example, the EU's Infrastructure for Spatial Information in the European Community (INSPIRE) aims at establishing common data typologies for transnational environmental assessments and environmental policies (European Commission, 2015b). In addition, national laws for the provision of and public access to spatial information were passed in recent years, for example, in Germany (BMUB, 2012) and Switzerland (GeolG, 2007). With these regulations, access to environmental and ES information can also be enabled, allowing potentially easier use and implementation of administrative information in a DSS, which would facilitate transparency, credibility and legitimacy, as previous studies have shown (e.g., Wissen Hayek et al., 2015; Ruckselshaus et al., 2015; Pettit et al., 2011; Cash et al., 2003).

Empirical studies in spatial decision-making have shown that the amount of information affects the quality of the decisions (e.g., Jankowsky and Nyerges, 2001; Jelokhani-Niraraki and Malczewski, 2014). For example, as the number of alternative locations or criteria available in the decision-making process increases, stakeholders also need an increasingly deeper understanding of the relations and dependencies of the locations or criteria to assess and prioritize them (JelokhaniNiraraki and Malczewski, 2015). Furthermore, recognition of relations and dependencies becomes more difficult, and users then tend to simplify their decision-making processes to avoid high cognitive demands for examining the information. Consequently, low-quality decision-making and a low level of consensus between decision-makers frequently occur (Jelokhani-Niraraki and Malczewski, 2015). Although the relevance of information integrated in a DSS facilitates the transparency, credibility and legitimacy of decision-making (Ruckselshaus et al., 2015), the best methods for representing information so that the users' decision-making process is most effectively supported and the level of information required for high-quality decisions remain unclear.

In general, to communicate is to transmit information so that it is understood and, typically, used to guide action. For environmental information, the relation and interaction between different environmental criteria make successful communication a complex, multifaceted task. This complexity is further increased by spatial information, which makes comprehensive understanding and, therefore, effective communication more difficult (Mors et al., 2010). The initially communicated environmental information hinders easy information transfer because of the multifaceted effects on other environmental criteria. Especially, the communication of combined environmental and spatial information can lead to complex socio-psychological interactions (Mors et al., 2010), including emotional reactions if recipients are personally affected or have a relation to an affected place (e.g., Veríssimo and Campbell, 2015; Rogge et al., 2011). As previous studies have shown, recipients can often cognitively link the communicated environmental criteria to landscape aesthetics (e.g., Junker and Buchecker, 2008). Such an extended perspective of non-DSS-included information (as they would be supported by landscape visualizations) can be based on either experience or knowledge of the place. These reactions can be identified over the course of participative landscape planning approaches in which stakeholders react and interact with provided information (e.g., Celio et al., 2014; Höppner et al., 2007). In contrast, a lack of information or criteria that are used for reasoning can affect the trust or confidence in a DSS, as there is a lack of completeness. Disinterest in participation or dissatisfying communication might be the consequence (Höppner et al., 2007). Most notably, not only the detail, comprehension and amount of information (e.g., indicators, criteria and localities) influence user emotions and behavior, but also the design of the presented information affects cognition and therefore the reasoning processes (Russo et al., 2014). Consequently, understanding the information requirements of DSS users can result in more comprehensive and improved communication and thus more effective and efficient decision-making due to the transparency, credibility and legitimacy of the information integrated in a DSS (Wissen Hayek et al., 2015; Ruckelshaus et al., 2015; Pettit et al., 2011). In summary, to determine how to provide the most effective and efficient information for users, two main aspects must be addressed: how to communicate environmental and ES information comprehensively and how to represent such information. Knowledge of these aspects can avoid negative effects such as a loss of trust and confidence, or emotional reactions that prevent an objective examination of the information (Pettit et al., 2011). Especially for DSSs, appropriate communication and presentation of information are important to support users with relevant and needed information in their personal decision-making strategy (Jelokhani-Niraraki and Malczewski, 2015; Vessey, 1991; Vessey and Galleta, 1991).

Novel techniques such as eye tracking (ET) make it possible to record humans' gaze and, thus, to research visual behaviors in a natural setting. With this technique, we can investigate how DSS users use information and apply a DSS. ET has been proven to be a helpful technique in user research, especially for the evaluation of visual stimuli in practical applications. With ET, the length and frequency that users look or gaze at particular areas of interest (AOIs) can be determined (Duchowski, 2007; Holmqvist et al., 2011). The position of the gaze is typically expressed using screen coordinates (i.e., pixels). From these basic screen coordinate measurements, various gaze metrics are derived in relation to the stimuli (screen display), such as the fixation duration or dwell time (i.e., how long a gaze is fixed on a certain AOI), fixation count (i.e., how often the gaze revisits an AOI), number of revisits of the AOIs and scan-path characteristics (e.g., length and speed of eye movements; Ooms et al., 2014). Although a new technique, ET has already been applied in many research fields, such as software engineering (e.g., usability tests; e.g., Jacob and Karn, 2003; Nivala et al., 2001), marketing (e.g., advertising placement, webpages, product label design; e.g., Goldberg et al., 2002; Pieters, 2008; Pieters and Wedel, 2004; Poole and Ball, 2006), psychology (e.g., reading, scene perception, visual search; e.g., Rayner, 1998, 2009; Recarte and Nunes, 2000) and landscape perception and design (Dupont et al., 2013; Duchowski, 2007). However, gaze behavior does not provide feedback about why DSS users focus on specific information. In other words, ET cannot be used to 
determine whether the visually perceived information is relevant for reasoning or decision-making. However, a combination of ET and cognitive interviewing enables an investigation of usability of provided information. To understand this interaction between the use of information integrated in a DSS and cognitive processes, cognitive interviewing, which has been designed to capture cognitive processes and is supported by a large body of methodological research, must be applied (Campanelli, 1997; Campanelli et al., 1991; De Maio and Rothgeb, 1996; Dippo, 1989; Esposito and Hess, 1992; Jabine et al., 1984; Jobe and Mingay, 1991, Jobe et al., 1993; Lessler and Sirken, 1985; Royston et al., 1986; Sirken et al., 1999; Willis et al., 1999; Willis and Schechter, 1997). Thus, by linking information provided by ET with knowledge of cognitive processes, users' manner of perceiving information provided by a DSS can be investigated.

With this study, we shed light on the usability of an ES-based DSS. We investigated what information is used and how this information affects users' cognitive processes and reasoning in decision-making. We designed a DSS that displayed ES information in various types of representation. Further, we developed an experimental design based on functions in application of ES information (Klein et al., 2015) to identify key types of representation for communicating ES information. Various functions in application and various experimental tasks were defined that prompted users to apply the information integrated in the DSS in various contexts. These functions in application describe the differences between the purposes the users were applying ES information. Klein et al.'s (2015) results showed that users demand or prefer specific display types or types of representation depending on the intention for using the ES information and thus on the specific function in the application. In the present study, during the experimental runs, the users' gaze behavior was measured with eye tracking to identify which ES information was used. We also developed a set of cognitive probing questions to investigate users' reasoning based on perceived information. Finally, to understand how users' attachment to a location influences their use of information, reasoning and decision strategy, we applied a split-sample design that separated users with and without connections to the region.

\section{Methods}

In the following section, we describe (1) how the ES information was presented by various types of representation integrated in the DSS and (2) how we determined specific user behaviors on the intention of applying the ES information. For the latter, we used ET parameters to analyze the participants' gaze characteristics in information use and cognitive interviewing to identify relevant information for certain decision-making and reasoning. To combine the methodologies, we developed a set of probing questions, specifically tailored to the study's tasks. Further, information on the participants' connections to the case study region were also collected to investigate whether familiarity with the region affects reasoning and use of the ES information. The measured ET parameters were analyzed with a repeated-measures analysis of variance (ANOVA) and linked to feedback from the cognitive interviews.

\subsection{DSS content and case study region characteristics}

The region is characterized by increasing settlements in total area through an expanding secondary sector (+87 ha) and higher average spatial demand per person ( $+18 \%$ on average; BFS, 2015). The resulting land-use conflict between fertile farming land and suitable settlement areas has led to a loss of ES and original landscape characteristics in the region, a development that could cause loss of attraction as a tourist destination (Brand et al., 2013). The landscape is further structured in small and often badly accessible or badly cultivable agricultural areas, especially in more remote areas. The most fertile and most accessible farming land is located at the bottom of the main valley directly adjacent to the city of Visp, which also recorded the highest increase in settlement area within the region (BFS, 2015; VSGIS, 2015). In the periurban to rural surroundings of Visp, the primary sector is still the most important source of income other than tourism (Brand et al., 2013).

The case study region in the Canton of Valais, Switzerland, covers a total area of $348.8 \mathrm{~km}^{2}$ and is home to 16,021 residents (as of 2013; BFS, 2015). The largest city, Visp, is located in the main valley, to which the valley of Saas is connected in the south and the valley of Baltschieder in the north (Fig. 1). The valleys are surrounded by alpine terrain. The Rhone River flows through the main valley. Twelve municipalities are located within the region, all within the Visp district: Baltschieder (658 $\mathrm{m}$ a.s.I.), Eisten (1,086 m a.s.I.), Saas-Balen (1,483 $\mathrm{m}$ a.s.I.), Saas-Fee (1,798 $\mathrm{m}$ a.s.I.), Saas-Grund (1,559 $\mathrm{m}$ a.s.I.), Saas-Almagell (1,672 $\mathrm{m}$ a.s.I.), Stalden (795 $\mathrm{m}$ a.s.I.), Staldenried (1,052 $\mathrm{m}$ a.s.l.), Visp (658 $\mathrm{m}$ a.s.l.), Visperterminen (1,378 $\mathrm{m}$ a.s.l.) and Zeneggen (1,370 $\mathrm{m}$ a.s.l.). The one exception is the village of Eggerberg ( $846 \mathrm{~m}$ a.s.l.), which is in the neighboring Brig district. 


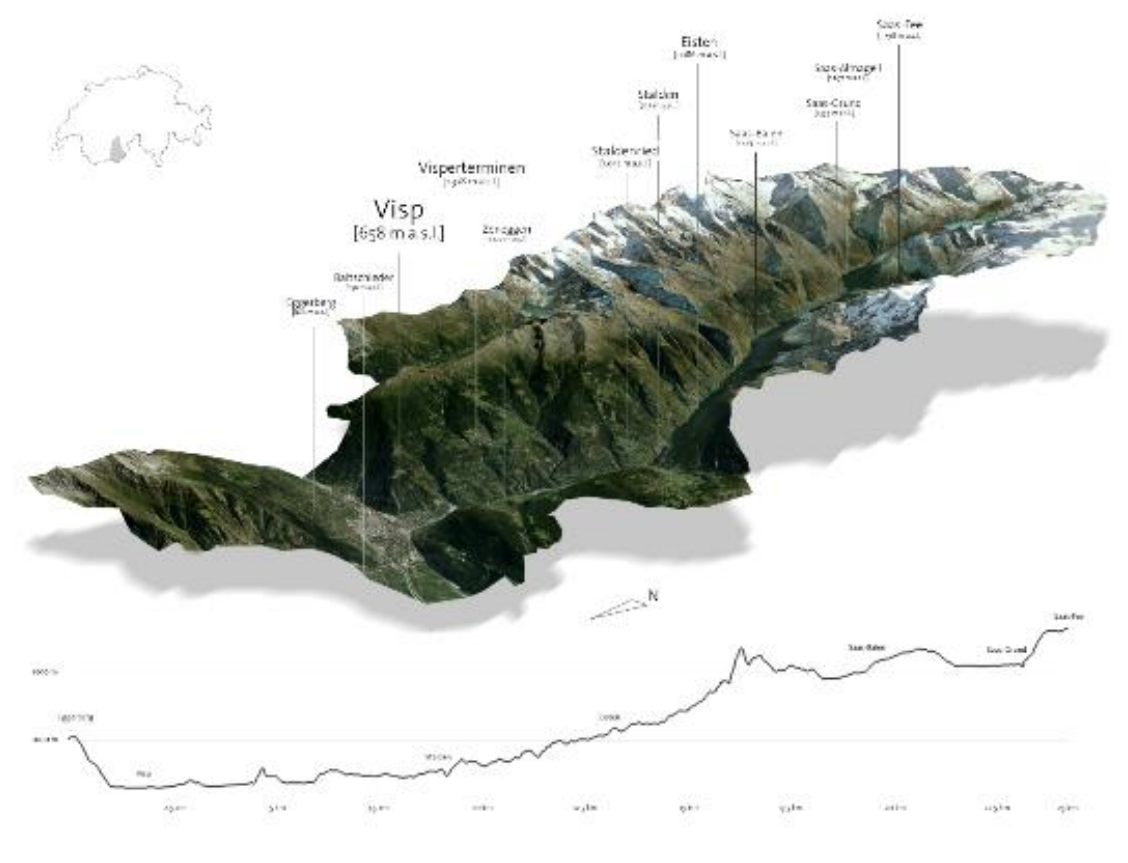

Fig. 1. Case study region, Visp district. The profile shows the bottom of the valley starting at the counter-slope in Eggerberg, down to Visp and upstream to Saas-Fee.

The DSS shows changes in land use and ES under various socio-economic and climate scenarios in the region. Mountain cultural landscapes that developed during centuries and millennia are undergoing rapid transformation, leading to a growing loss of the ecosystem services (e.g. food production by agriculture) demanded by people living in and outside these areas. Whereas settlement expansion is nurtured by a better transportation infrastructure and the expansion of service and manufacturing industries, structural changes in the agrarian sector have led to an intensification of agricultural land-use practices and the associated decline in semi-natural habitats. The content is based on model outputs generated by a modeling framework consisting of a spatially explicit agro-economic optimization model linked with a cellular automata based settlement allocation model. The GIS model couples agro-economic land allocation modeling and settlement expansion modeling to explore the effects of spatial planning instruments on ES provision. The modeling framework links two models: a recursive-dynamic agent-based land-use model (the Alpine Land-Use Allocation Model, ALUAM) and an automated settlement transition model (the Dynamic Settlement Allocation model, DSA). Both models are spatially explicit with a resolution of $100 \mathrm{~m} \times 100 \mathrm{~m}$ per raster cell. Based on a land-use map as well as agro-economic input data, the ALUAM simulates land-use changes and ES provision in agriculture and forestry under different scenarios by maximizing the aggregated income of farmers and foresters in the region. The resulting land-use map was subsequently transferred to the settlement allocation model DSA. The DSA then calculated the demand for new settlement area in the region and allocated the required number of settlement cells based on the location factors and the ES. The scenarios demonstrate that spatial planning is key for shaping mountainous landscapes and supporting ES. Cooperation among municipalities and an explicit consideration of ES can inform ES trade-off decisions under the pressing demand for land.

For this study, two scenarios were selected and visualized on the DSS. In scenario A, new settlement cells can be allocated freely adjacent to existing settlements, and municipalities are cooperating to distribute the new settlement cells. In scenario B, new settlement cells are allowed only in designated building zones.

\subsection{DSS integrated types of representation}

Based on Klein et al.'s (2015) work, an experimental design was developed to identify types of representation for communicating ES information. The method builds on analyzing participants' behavior while they use ES information. Fig. 2 shows the DSS on a display monitor, which was used as the DSS user interface for the experiment. 


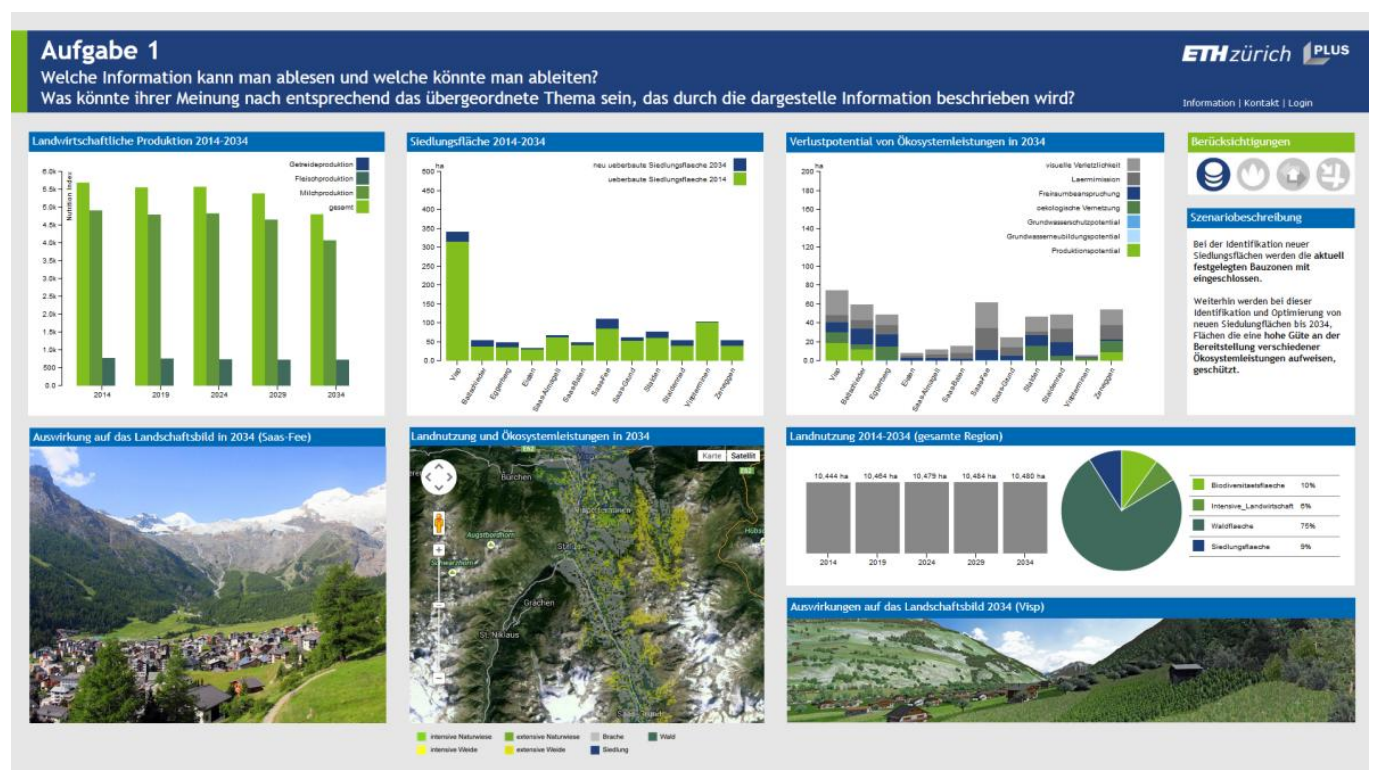

Fig. 2. Decision support system with ecological services information provided by various types of representation.

All ES information in the DSS was available in more than one representation; thus, the participants could prioritize which representation type they want to use for different tasks. Table 1 shows how the information of the various types of representation was linked. Direct information (grey cells, Table 1) means that the specific information could be read out directly from a representation type, whereas linked information (yellow cells, Table 1) means that the same information content was also represented by another representation type. Potentially linked information (blue cells, Table 1) means that information can be connected to information from other types of representation in a more inferable way. Last, inferable information (green cells, Table 1) indicates that a deeper understanding of the data was required for further information gain. For example, by switching between the two scenarios the participants could have read that the settlement area was constant over the area but varied among the municipalities. Such varying settlement area deployment on municipal level also affected potentially different increases in noise stemming from increased traffic because of additional settlement areas in peri-urban municipalities. However, this information was not shown in the DSS, and participants had to be aware of the potential consequences of peri-urbanization to draw such a conclusion. 


\section{Table 1}

Links and interdependencies between types of representation and the information content.

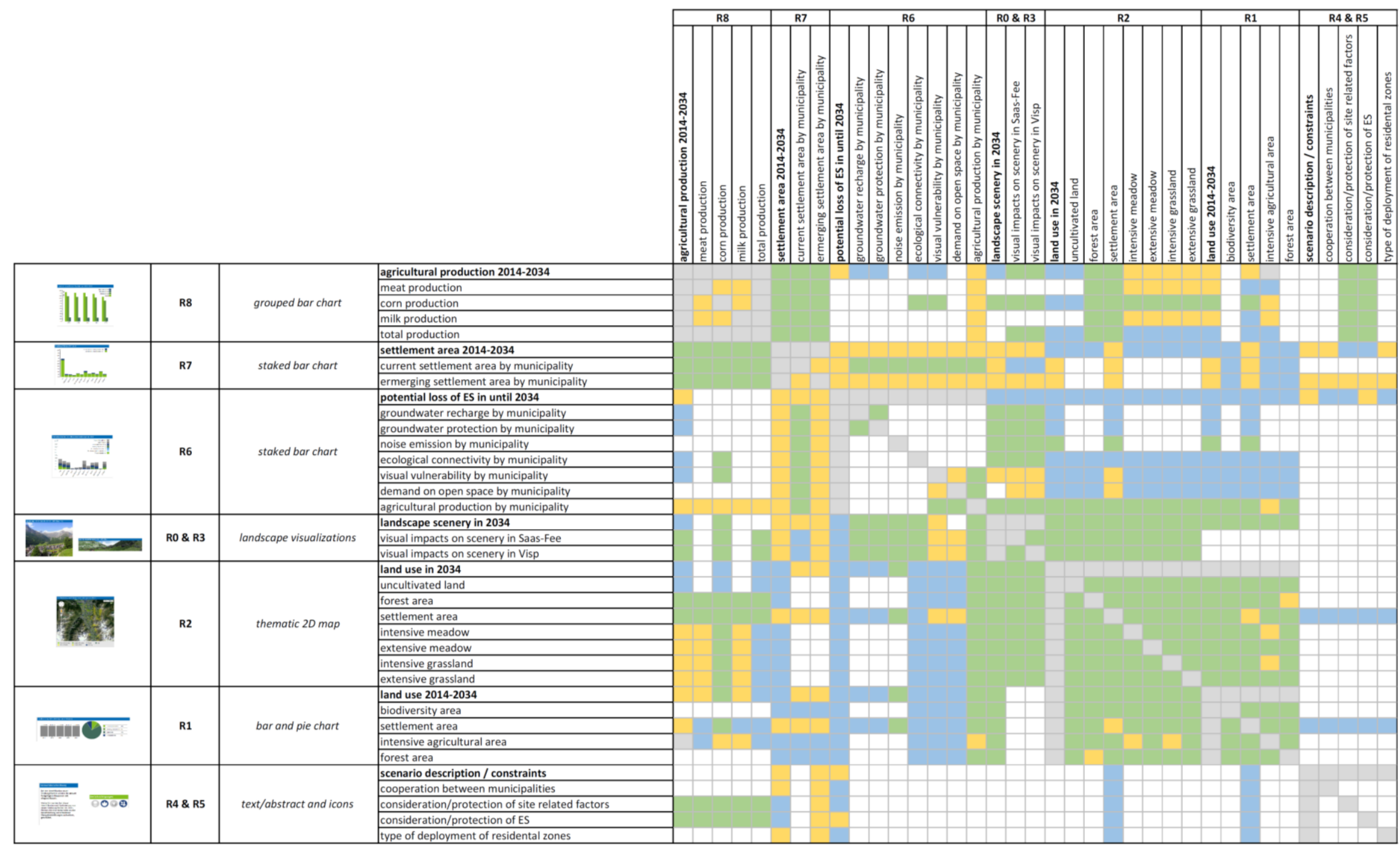

direct information

linked information

potentially linked information

inferable information 
All information describing or resulting from a scenario (e.g., scenario definition and constraints, ES loss and land-use impacts) was grouped as AOls, which were used as the units for the ET experiment (Fig. 3). The AOls corresponded to the main representation categories identified in Klein et al.'s (2015) demand analyses. The AOls were comprised of visual and non-visual representations and covered similarly sized areas on the DSS screen, which consisted of eight AOls. A realistic landscape visualization (R0) showed a view of a settlement area in the municipality of Visp in 2034. In addition to changes in the number of buildings, the visualization showed agricultural changes with different types of meadow (intensive vs. extensive use) varying in growth height and vegetation composition. Information on land uses over time from 2014 to 2034 in 5-year increments was provided by a combined bar and pie chart (R1). This information was available at the municipal and regional levels. Additionally, this representation allowed the participants to investigate either the total area of the landuse type per time step or the proportions per year. Using this representation, the participants related information from finer scales (e.g., municipality) to the entire region. In a thematic 2D map (R2), land-use information was presented as a raster map, which showed intensive and extensive meadows and pastures, as well as settlement areas, forest and uncultivated land on top of aerial images and thematic map layers. The participants interacted with this thematic 2D map by zooming and panning, for detailed inspection of the sites (e.g., investigate the location of the municipalities). In the photorealistic landscape visualization (R3), the municipality Saas-Fee in 2034 was shown. Between the scenarios, the number of buildings in this visualization changed. A short scenario description was provided as a text/abstract (R4) that contained information about the scenario preconditions. Additionally, scenario constraints were shown with icons (R5) for quick identification of the differences between the scenarios. The various icons were explained at the beginning of each trial. Furthermore, mouse-over tool tips were available for the icons. The potential loss of various ES (noise emission (recreation/quietness), visual vulnerability (aesthetics), demand on free space (recreation nearby), ecological connectivity (habitat function), agricultural production (food production) and ground water (protection, ground water recharge) in 2034 was displayed as a stacked bar chart (R6) by municipality. The settlement area in 2014 and 2034, again differentiated by municipality, was also displayed as a stacked bar chart (R7). A grouped bar chart (R8) was used to depict the development of agricultural production in 5-year increments for various agricultural products (i.e., meat, crop, milk and total).

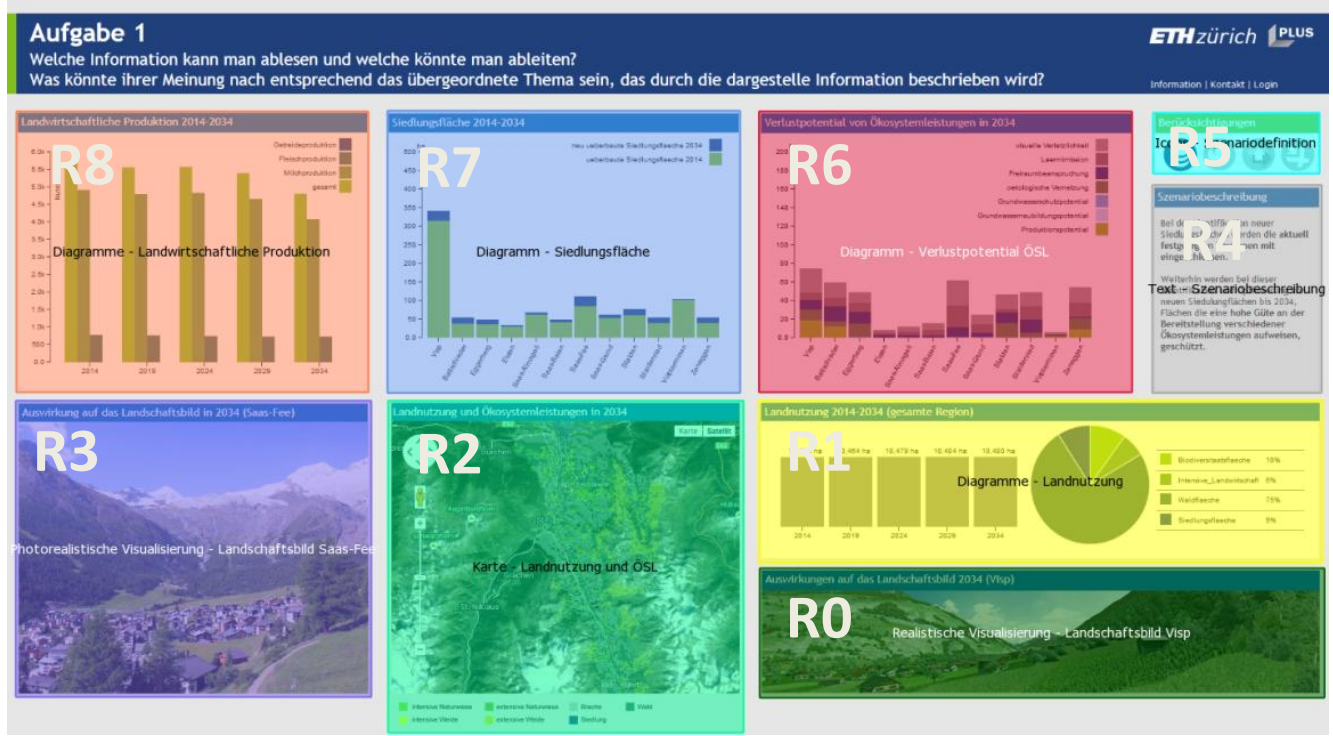

Fig. 3. Various types of representation (RO-R8) defined as the areas of interest (AOIs).

Data from the modeling framework was provided as an ASCII table. These data were either converted to a Key Markup Language (KML) map presented by Google Maps API (http://developers.google.com/maps) or linked to various chart visualization libraries using various D3js JavaScript libraries (www.d3js.org). KML and Google Maps were used for the thematic 2D maps (R2), whereas the diagrams (R1, pie and bar chart for the whole study region land-use information; R6/R7, stacked bar charts for the potential ES loss, and current and new settlement area; R8, grouped bar chart for agricultural production) were generated with JavaScript. Both landscape visualizations were created separately with a photo montage in Adobe Photoshop (R3: photorealistic landscape visualization) or with 3dnature VNS software (www.3dnature.com), (R0: realistic landscape visualization). In addition, both landscape visualization types represented the land-use characteristics of the modeled scenario data. The user interface was programmed in web-based HTML language. HTML-based tags contained the various types of representation.

\subsection{Study sample}

The participants $(n=101)$ were university students who received invitations to participate in their classes and by e-mail. The study lasted from March to May 2015. The study participants were subdivided in two user groups: The first group ( $n=$ 
50) had no direct connection to the region and consisted of spatial planning or environmental science students from the Federal Institute of Technology (ETHZ) in Zurich, and the second group $(n=51)$ consisted of persons with a direct connection to the study region or the region of Valais and were tourism students at the Haute école spécialisée de Suisse occidentale (HES-SO) Sierre. Both student groups had a common background in sustainable planning. All participants were undergraduates or had received a bachelor's degree; $62.7 \%(n=64)$ of the participants were female, and $37.3 \%(n=38)$ were male. Most participants were between 21 and 30 years old $(82.4 \%, n=84)$; only $6.9 \%$ were 20 years or younger $(n=$ 7). More than half ( $56.9 \% ; n=58)$ of the participants had previous personal experience with the topic, and $52 \%(n=53)$ had worked on the topic as part of their occupation or studies. Nearly a quarter of the participants in the second group (24.5\%; $\mathrm{n}=25$ ) indicated that they personally or their family members or friends would be directly affected by the impacts of the scenarios.

\subsection{Experimental design}

To cover a broad set of functions in application (i.e., the intention to use the information as described by Klein et al., 2015), a set of nine tasks (nine stimuli) was defined to analyze how users applied the ES information integrated in the DSS when they faced a question to which the answer could be derived from the information. The definitions of the possible basic functions of ES information in the DSS are based on Brömmelstroet's (2013) work and consist of informing about, communicating and analyzing content, which also describes the intention to use the information integrated in a DSS. In a previous study (Klein et al., 2015), we developed a more detailed set of these functions in application to differentiate among the detailed properties of various demands (e.g., exploration of content, spatial analysis, support of assessment, Table 2). With these more concrete functions in application, it becomes possible to understand the relevant stages of individual reasoning and decision-making processes (Klein et al., 2015; Keller, 1997; Simon, 1960; Sugumaran and de Groote, 2011). Table 2 shows the tasks participants were exposed to with the related functions in application.

Table 2

Definitions of tasks based on the functions in the applications.

ID

Function in application Task

Time

$4^{\prime}$

What information can be extracted or inferred from the DSS?

What might the overall topic of the information?

Task $2(\mathrm{~T} 2)^{* *} \quad$ Communication of content Please describe the scenario characteristics.

Please show how the scenarios vary. How do you

Task $3(\mathrm{~T} 3)^{*}$

Exploration of content/ support of analyses

Task $4(\mathrm{~T} 4)^{*} \quad$ Support for spatial analyses

In which locations are the biggest difference(s)

between the scenarios?

Task $5(\mathrm{~T} 5)^{*} \quad$ Support for estimates/ scenario development

Task 6 (T6)* $\quad$ Support for assessment

Task 7 (T7)* $\quad$ Support for aesthetic assessment/decision-making

Please estimate how the scenarios would result if there were no new settlement area in the municipality of Visp in 2034.

Please assess the impacts of the new settlement areas in $\mathbf{2 0 3 4}$ on the municipalities of Saas-Fee and Visp.

Please assess and decide which scenario provides the most beautiful landscape.

Task 8 (T8)* $\quad$ Support for decision-making

Please assess and decide for this scenario which one is the most ecologically sustainable.

Please assess which of the scenarios provide the

Support for aesthetic most beautiful landscape. assessment/decision-making
Scenario number

$* * * *$

1
2

$2^{\prime}$

$30 "$

\footnotetext{
* Randomly deployed in the experiment sequence between T1 and T9

** The participant was asked to explain simultaneously while the information was shown the scenario characteristics to the study 

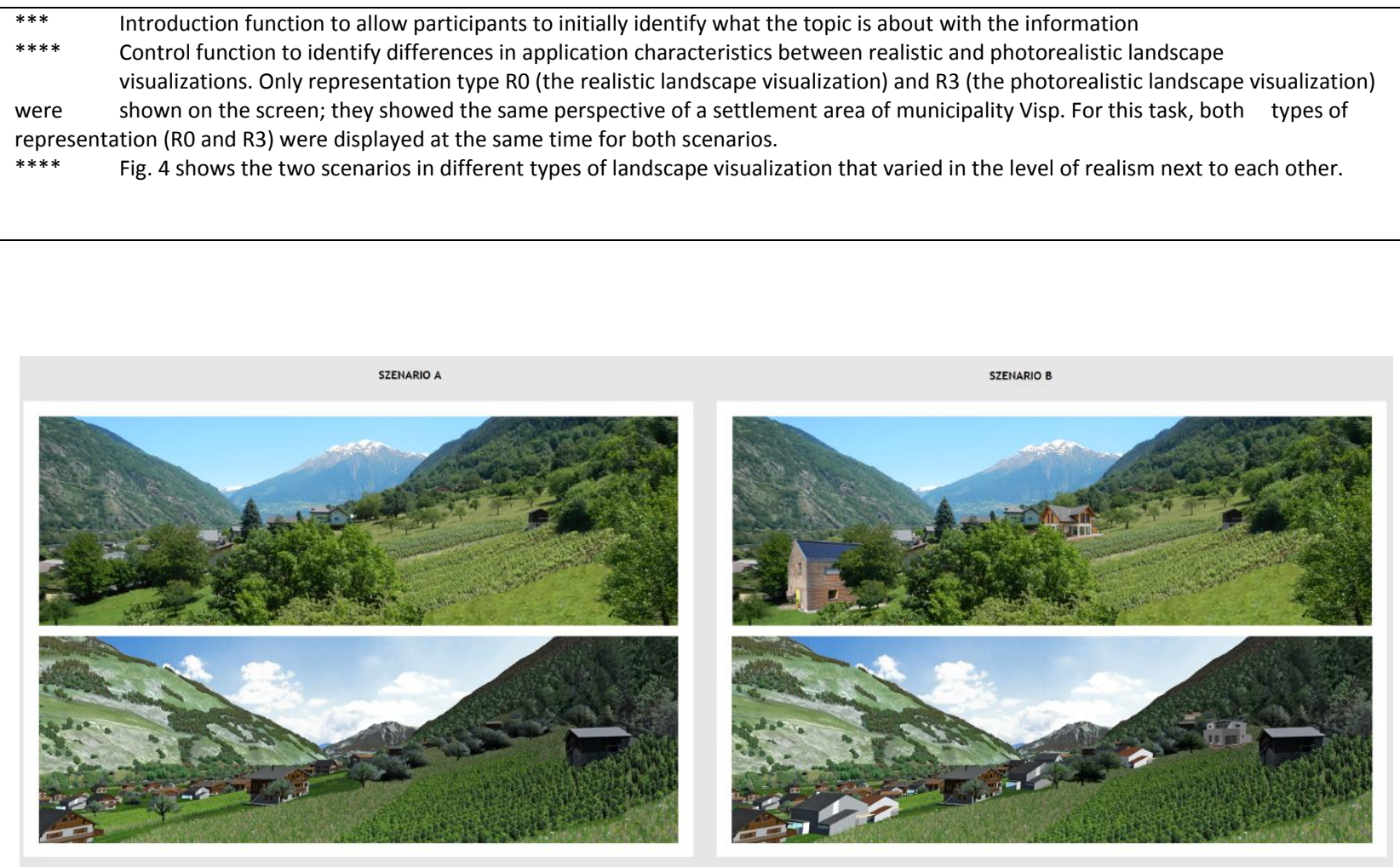

Fig. 4. Controlling task (Task 9) for identifying possible bias through the level of realism of the landscape visualizations.

All participants were shown a sequence of web-based HTML screens starting with a welcome site, an ET calibration site, and a thematic introduction, followed by experiment instructions and background information on the information by types of representation. The participants started each task whenever they were ready. As a reminder, the tasks were presented at the top of the DSS screen. The information was shown for only a limited time. During these time sequences of 2 to 4 minutes (depending on the task), the participants were asked to derive the answer for a task by concentrating on the information without talking to the study attendant (with exception of Task 2). After the set amount of time, the DSS and its information panels disappeared, the task or question was repeated and the participant was asked to answer. In addition to the main question of the task, two to three questions were asked to identify the participants' cognitive processes and to understand their reasoning (see section 2.5.2). Depending on the specific task, information on a second scenario was also available on a second screen, and the participants were allowed to switch between the screens. The task sequence was randomized, with the exception of Tasks 1 and 9 (Table 2). The data gathered in Tasks 1 and 9 were not considered for the ANOVA, because these data had either an introductory or control function. The complete study required 40 to 60 minutes per participant, depending on the rate and complexity of the answers. The total time that the information screens were presented to the participants was 18 minutes 30 seconds (Table 2).

\subsection{Data acquisition, processing and analysis}

\subsubsection{Eye tracking}

In the study design, the participants were asked to wear mobile SMI ET glasses (www.smivision.com) to capture gaze behavior when they looked at the DSS information on a 24 inch 16:9 monitor display with a resolution of $1920 \times 1080$ pixels. The ET glasses were a binocular eye tracker, which captured both eyes and computed the gaze position in a scene image. The scene image was captured by a scene camera located in the center of the glasses. To obtain accurate gaze positions, each participate had to perform a system calibration. The ET glasses measured the gaze pointer for both eyes with automatic parallax compensation with $30 \mathrm{~Hz}$. Gaze pointer accuracy of $0.5^{\circ}$ to $1.0^{\circ}$ and a tracking range of $80^{\circ} / 60^{\circ}$ horizontal/vertical assured the precise localization of the participant's gaze on the $1280 \times 960$ pixel scene video with $24 \mathrm{fps}$ that was captured by the ET unit.

BeGaze $^{\mathrm{TM}}$ analysis software by SMI (www.smivision.com) was used to process the raw ET data generated in the experiment. With BeGaze ${ }^{\mathrm{TM}}$, we calculated the variables dwell time, fixation count and revisits of the AOls, which were also used in the statistical analyses as suggested by Ooms et al. (2014), Dixson et al. (2014) and Vidal et al. (2013). The number of revisits of an $\mathrm{AOI}$ indicates its complexity: Users have to revisit the $\mathrm{AOI}$ repeatedly to link, analyze or compare the presented information together with other information. Dwell time and fixation count quantify the use of AOls for the task at hand and identify the potential relevance of the information for answering the task question.

\subsubsection{Cognitive interviewing}


Cognitive interviewing is a general method that critically evaluates the transfer of information (Willis, 2005). So that respondents understand the questions correctly, technique and question design are important for cognitive interviewing. Think-aloud and verbal probing approaches assume that participants can report and even evaluate their own cognitive processes (Willson and Miller, 2014). However, the think-aloud method in combination with ET has been criticized (Oh et al., 2013). Verbal probing uses an afterwards/debriefing survey design that is more suitable in combination with ET and is appropriate for cognitive and decision process investigations (Caspar et al., 1999; Willson and Miller, 2014). Therefore, we decided to apply the verbal probing method.

In the debriefing survey, we included the four questions presented in Table 3. In the recall and construct strategy question, we asked for an explanation. To identify the overall ability and experience of using ES information to fulfill a task, in the comprehension question the participant was asked whether completing the task or answering the question was difficult and to identify his or her overall ability and experience. The participant rated the question on a binary scale ranging from difficult to easy. The confidence identification question was posed to identify the participant's confidence to investigate if and potentially why there were issues in fulfilling the task. The participants answered according to a 4-item Likert scale: not at all sure, not sure, sure and very sure. When the task included special terms (e.g., Tasks 7 and 8 ), we used another question to investigate the participant's term comprehension interpretation to identify whether there was bias through an incorrect definition or even a misunderstanding.

The participant's answers to the recall and construct strategy question were recorded in a protocol. In this protocol, all rationales by participants were collected and assigned to types of representation (AOIs) or further categories. For example, if the participants reasoned concretely by $\mathrm{AOI}$ assignable information, indicators or characteristics or stated therefore that he or she perceived this information by a specific AOI, the reasons were linked to these AOls within the protocol. Furthermore, the various characteristics, elements and scales of the information provided by the different types of representation were protocolled (e.g., buildings, trees). We added a group of other scales that included extended region, if the participant wanted to reason by facts of outside the region at a larger spatial scale. We also added a group of specific other locations, if the reasoning was related to specific locations outside or inside the region. Other scales were elevationbased location, if the participant's rationales were based on altitude, and thematic-based location, if the participant related the location to specific areas that were defined by another topic (e.g., "everywhere there, where..."). These additional scale categories seemed necessary to compare the participant sample groups, as the participants with connections to the region could potentially have based their rationales on their knowledge of the place. Another category other rationales was added, if the participant's reasoning was not based on the DSS information or indicators.

\subsubsection{Statistical analysis}

For each of the ET parameters dwell time, fixation count and revisits, we compared the average value per representation type and task. We used a repeated-measures ANOVA with IBM SPSS Statistics version 22 (www.ibm.com/spss), in which the participants were entered as random effects, because repeated measures were performed per participant (i.e., each participant fulfilled all nine tasks by using the types of representation). Additionally, we compared differences in the average ET parameters between the groups with and without a connection to the region. To determine the attractiveness of the types of representation, we also investigated the cognitive interview protocols with a descriptive analysis.

Table 3.

Cognitive probing question set by tasks (stimuli). Translated from German.

ID Recall and construct
strategy (1)

Task $1 \quad$ Why do you think this is the topic described by the information?

Task 2

Task 3 Why did you interpret the differences in this way?

Task $4 \quad$ Why do you think that the biggest changes or impacts can be found specifically in these locations?

Comprehension
identification (2)

\section{Confidence identification (3) \\ How certain are you that this is the topic for which the information is provided?}

Was the question easy or difficult to answer and why?

Was the question easy or difficult to answer and why?

Was the question easy or difficult to answer and why?

Was the question easy or difficult to answer and why?
How certain are you that you have communicated the scenario correctly? How certain are you that you interpreted the differences correctly? How certain are you that you identified the locations with the biggest changes or impacts?
Term interpretation (4) 
Task 5 Why exactly do you think that these would be the impacts?

Task 6 Why exactly do you think that these would be the impacts?

Task 7

Why do you think that the chosen scenario provides the most beautiful landscape?

Task 8 Why did you think that the chosen scenario is ecologically sustainable?
Was the question easy or difficult to answer and why?

How certain are you of your estimates that these would be the consequences?

Was the question easy or difficult to answer and why?

Was the question easy or difficult to answer and why?

How certain are you about your assessments that these would be the impacts?

How certain are you that you have really chosen for the scenario the most beautiful landscape?

How certain are you that you really have chosen the most ecologically sustainable scenario?
What do you understand under "beautiful landscape"?

What do you understand under "ecologically sustainable landscape"?

Task 9* Why do you think that the chosen scenario provides the most beautiful landscape?

* Task 9 is defined as a control task to identify potential bias of the landscape visualization types (realistic vs. photorealistic) (see Table 2, Fig. 4)

\section{Results}

The results show that there are specific preferences in using ES information provided by types of representation. This user behavior depends on the function in application of the ES information. In other words, the intention of information use determines the preference for a certain representation type. For example, visual information in general was more preferred compared to texts or abstracts. To answer general questions, information presented on a small scale was preferred to large-scale information. However, information on a large scale and therefore more detailed information could improve the quality of the answers. The participants' connection to the site often influenced their reasoning and therefore the use of the scale of information. Such effects depend on the information depth and detail provided by a representation type and on the experience that participants have with specific types of representation, as well as the availability to link their knowledge of the place to the information provided. Participants with a connection to the region for which the ES information was provided exhibited other behavior than participants without a connection to the region. This effect was also identified in the cognitive interviews.

\subsection{Eye tracking}

Depending on the information necessary to solve a certain task, participants exhibited different strategies for acquiring relevant information, by using the various types of representation. Fig. 5 shows this different use of the types of representation by task. This behavior varied for all tasks, and strong diversity in the preferred information by types of representation existed. Knowledge of place further affected the participants' reasoning and decision-making strategy. The ET data showed a significant relationship between tasks and types of representation (Fig. 5; Huynh-Feldt's sphericity test (dwell time: $p=0.363$; fixation count: $p=0.398$; revisits: $p=0.487$ ). The univariate analysis results for the ET parameters of the types of representation (AOIs) showed high dependencies on tasks and therefore preferences depending on the intention to use ES information (dwell time: $p=0.000, F=26.888, d f=17.410$; fixation count: $p=0.000, F=27.757$, $d f=19.117$; revisits: $p=0.000, F=22.093, d f=23.385)$. Because the results for the $E T$ parameters dwell time and fixation count (Table A2 and A3) were almost identical, we focus on dwell time in the following paragraphs.

The value of revisits of an $\mathrm{AOI}$ can be seen as an indicator of the complexity of a representation type. It can be inferred that if a representation type contains either comprehensive information or the information is difficult to remember, participants revisit a representation type more often. However, it is remarkable that types of representation with a high revisit count were preferred for specific tasks although the required information was available from other types of 
representation with a lower revisit value (i.e., types of representation that were easier to read). Consequently, it seems that the complexity of the ES information does not discourage participants if it is in line with their intention to apply the DSS (function in application).

The following results indicate that the participants also made assumptions about the effectiveness of the types of representation. This was particularly influenced by titles of types of representation, from which the participants interpreted their relevance for the tasks. For example, the titles for R0 and R3 were about landscape scenery, but R6 included information about landscape aesthetics. In contrast, R0 and R3 were limited by their information but were preferred for Task 7. This behavior seems to have been based on experience or expectations of representation type's title or even characteristics. The participants reported afterward that they had estimated, because of the time limitation, from which representation type they could receive the most supportive ES information to answer a task-specific question. Especially, such behavior was identified for Task 4 and Task 7, where thematic 2D map (R2) for a spatial analysis and landscape visualizations (R0 and R3) for an aesthetic assessment/decision-making were mostly used. The most supportive information for both tasks was provided by the stacked bar chart (R6) that contained the indicator about the visual vulnerability, whereas the information content of the preferred types of representation used for the tasks was either limited to a location (R0 and R3) or consisted of generic land-use information (R2).

Further, interactive types of representation, for example, provided by interactive pie and bar chart (R1) and thematic $2 D$ map (R2), were not used above-average. The interactive functionality of these two types of representation was used only if the participants recognized the relevance for specific tasks, as it was given by Task 4 (support of spatial analysis).

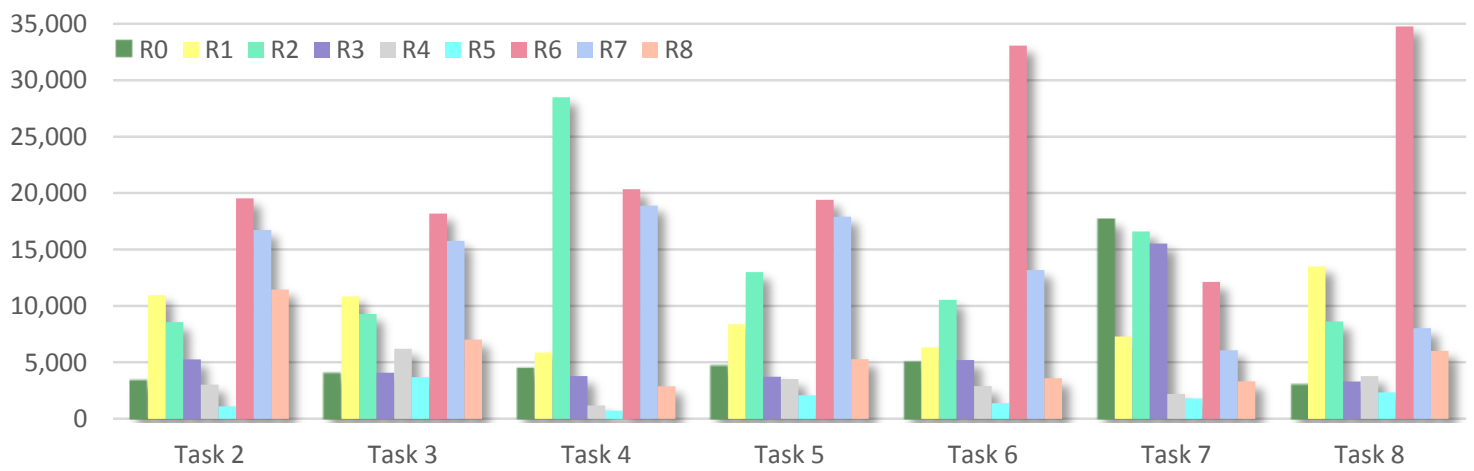

Fig. 5. Estimated mean dwell times [ms] for the types of representation separated by tasks, $n=101$ ( $n=50$ without/ $\mathrm{n}=51$ with a connection to the case study region).

Finally, texts/abstracts were the most unappealing types of representation. R4 and R5 consisted of texts or abstracts, and we observed that specifically for these types of representation the dwell times were shorter than average (Fig. 5). However, in this study both types provided important information about the scenario conditions; the texts explained the scenarios (R4) and therefore provided easy differentiation between the scenarios. Even in Task 2 (support of communication), in which the participants were asked to communicate the scenario story face-to-face while the information was displayed, the text was mostly ignored. The same occurred for Task 3 (exploration of content), on which the participants had to explain the differences between the scenarios: R4 and R5 offered the required information but were mostly ignored.

For all tasks with the exception of Task 7, significant differences in the dwell times of the types of representation between the sample groups were identified (Fig. 6). For face-to-face communication (Task 2), participants without local knowledge used significantly more generic information provided by the types of representation on a small display scale (R1, R4, R5, R6). In contrast, the participants with a connection to the region preferred types of representation that provided location-specific ES information (R0, R3, R2). For scenario exploration or analysis (Task 3), participants with no connection to the region and therefore without local knowledge used the scenario descriptions (R4) and information about the potential ES loss (R6) to a significantly higher degree than the participants with local knowledge. This user behavior seemed to be contradicted by the data on spatial analysis in Task 4. However, this behavior can be explained by a lack of local knowledge: Participants without local knowledge spent more time with the map (R2) overall as they first needed to locate the municipalities before proceeding with information required to solve the original task (R7, R6). This effect can be also identified for Task 6 and the impact assessment of two municipalities (Task 6). The participants without knowledge of the location were required to initially locate both municipalities in the region before they performed a comprehensive assessment. A similar effect can be identified for the estimates of the indicators that were not represented and scenario development (Task 5), where participants without a connection to the region relied significantly more on information about the current and future sizes of the settlement areas within the municipalities (R7), as it explains a triggered event for potential ES loss (R6). In addition to the map (R2), landscape visualizations (RO, R3) were preferred by the participants without knowledge of place, whereas participants with a connection to the region used information that was not provided by the DSS significantly more (R8). At least for decision-making (Task 8), participants with a connection to the region also considered aesthetic information (R3) significantly more than participants without a connection. Thus, participants with a connection to the region tried to more comprehensively use the information and included rationales that were not 
provided by the DSS triggering a comprehensive and more complex cognitive process (compare Task 2) than participants without a connection. This characteristic of task-specific preferences in ES information emphasizes the heterogeneous user demands due to their knowledge of place and therefore the resulting reasoning or decision-making strategy (see section 3.2.).

We also identified that participants generally spent more time on the photorealistic landscape visualizations than on the realistic landscape visualizations as identified by Task 9 (Fig. 6, see also Fig. 2). The reason for this participant behavior was the level of detail in the visualizations and therefore the number of visualized landscape elements and the time required to identify them. However, landscape visualizations with a higher level of detail supported improved landscape recognition as the participants with a connection to the region more easily identified the location presented by the photorealistic landscape than by the realistic landscape as was reported in the cognitive interviews.

More details about the differences between the participant groups and the ET variables are given in the tables in the Appendix.

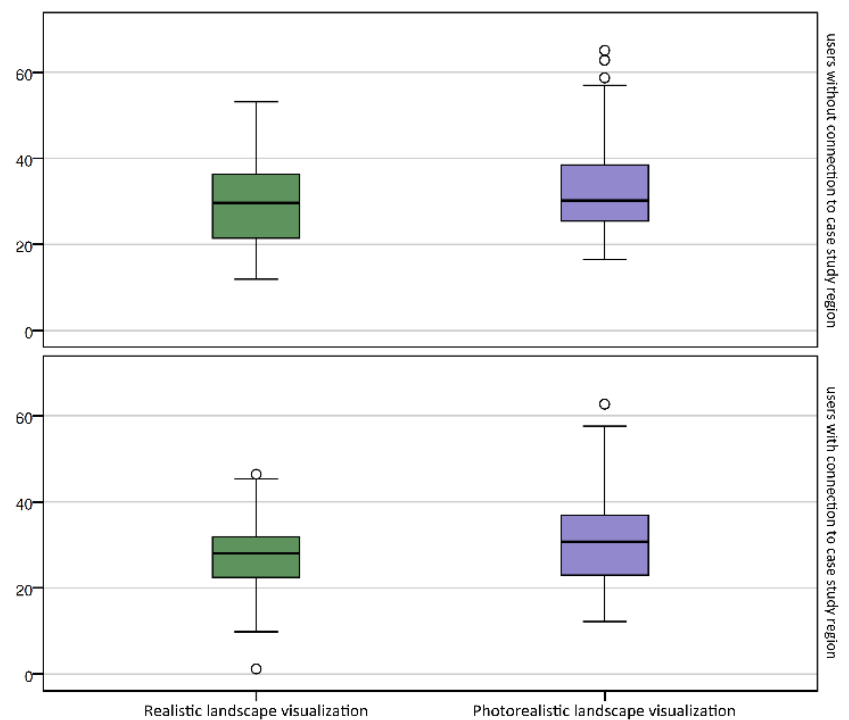

Fig. 6. Differences in using [dwell times in $\mathrm{ms}$ ] landscape visualization types ( $\mathrm{RO}$ and $\mathrm{R} 3$ ) and therefore preferences in level of detail between the participant groups. 

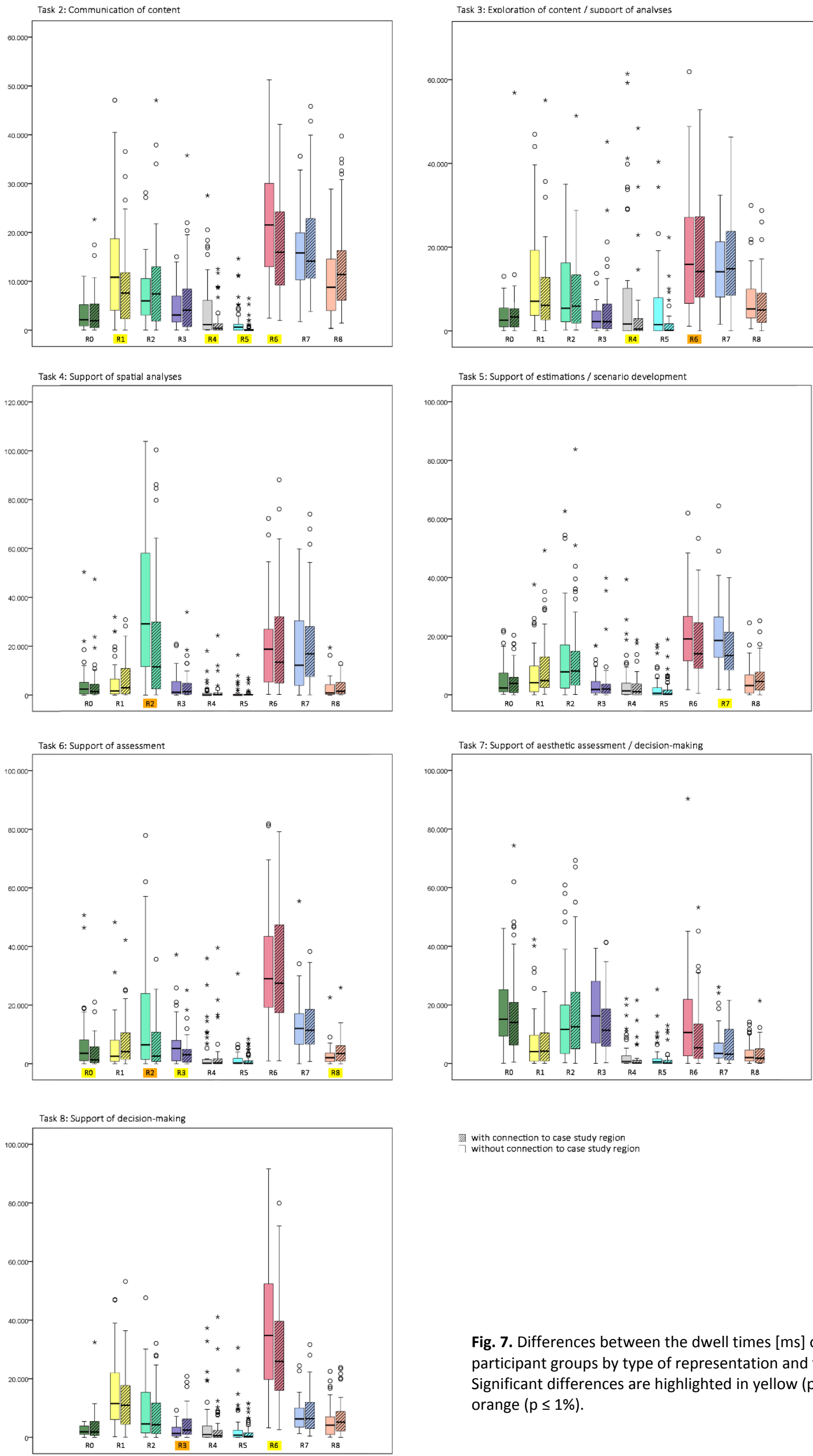

With connection to case study region
7 without connection to case study region

Fig. 7. Differences between the dwell times [ms] of the participant groups by type of representation and tasks. Significant differences are highlighted in yellow $(p \leq 5 \%)$ and orange $(p \leq 1 \%)$. 
Results of the cognitive interviews showed that the participants' reasoning strategy was task specific. As with the eyetracking study, in the interviews, we found that certain types of representation were preferred for specific tasks, because the participants reasoned by concrete information characteristics that were provided by only a single type of representation. Rationales brought up in the interviews often related to the scale of the preferred information. Interestingly, especially participants with knowledge of the location reasoned about the scales and with information/indicators that were not provided by the DSS although relevant information was provided to answer the question. Such a deviation from the provided information reflects that integrated ES information in the DSS potentially triggers the direction of the cognitive process and shows simultaneously that not all relevant topics were or even could be provided by the DSS that are required by participants for reasoning or decision-making.

Results of the cognitive interviews supported the results provided by the ET experiments; participants with a connection to the region generally reasoned more often with information not provided by the types of representation $(12.66 \%$ of the total reasoning was based on other information) than the participants who had no connection to the region (only $4.2 \%$ of their total reasoning was based on information not provided in the DSS). In addition, the scale selected by the participants varied. Participants with local knowledge preferred the municipality scale (59.62\% of reasoning) and other scales (6.69\%). Participants without a connection to the region reasoned less about these scales in total (municipality scale: $54.33 \%$, other scales: $3.91 \%)$ but used more general information about the total region as scale of reasoning $(32.98 \%$ of total reasoning, compared to participants with connection: $25.11 \%)$.

The reasoning for aesthetic assessment and aesthetic decision-making (Task 7) varied considerably between the participant groups. Participants without a connection to the region reasoned more based on aesthetic values provided by the landscape sceneries (RO, R3), whereas participants with local knowledge used the potential loss of ES in municipalities (R6) for reasoning. This reasoning strongly varied between the two participant groups by non-explicit aesthetic decisionmaking for selecting the more sustainable scenario (Task 8). Here, participants with a connection to the region reasoned about the municipality scale in combination with scenario description (R5) and about indicators that were not presented, whereas participants without a connection to the region based their reasoning on the potential loss of ES (R6).

Using cognitive probing questions, diversity in knowledge/experience (comprehension identification) and understanding (confidence identification) were identified between the participant groups. Statistically significant differences existed between the participants' ratings for the level of difficulty for fulfilling a task, as well the belief in their reasoning. For example, in Task 2 (communication of content) both groups rated their confidence in their reasoning. Participants without a connection to the region considered this task to be easier than participants with local knowledge (mean value difference = $0.304, p=0.027, t=2.237$ ). Task 4 (support of spatial analysis) also showed very significant differences between the groups in the difficulty of fulfilling the task. Participants with a connection to the area rated this task as easier than participants without (mean value difference $=0.268, p=0.004, t=2.947$ ). Both significant differences can be explained by differences in local knowledge: In Task 2, participants with local knowledge exhibited more complex thinking and tried to consider other aspects than those provided by the DSS. However, they struggled to communicate about the scenario and their thoughts. This changed in Task 4, where local knowledge helped the participants directly analyze and infer spatial differences more comprehensively and complexly with other rationales, as opposed to participants who had no connection to the study area who had to spend time locating the municipalities first.

An investigation of the ET results compared with participant reasoning determined by cognitive probing (compare Fig. 7 and Fig. 8) illustrates that types of representation that showed information on a smaller scale were generally used to answer general questions about the region. For example, charts with information about the total region were preferred instead of information grouped by municipality, or to define the ecologically more sustainable scenario in Task 8 , participants compared the total land-use information with potential ES loss by municipalities. More details about the differences between the participant groups and cognitive protocols are given in the tables in the Appendix. 

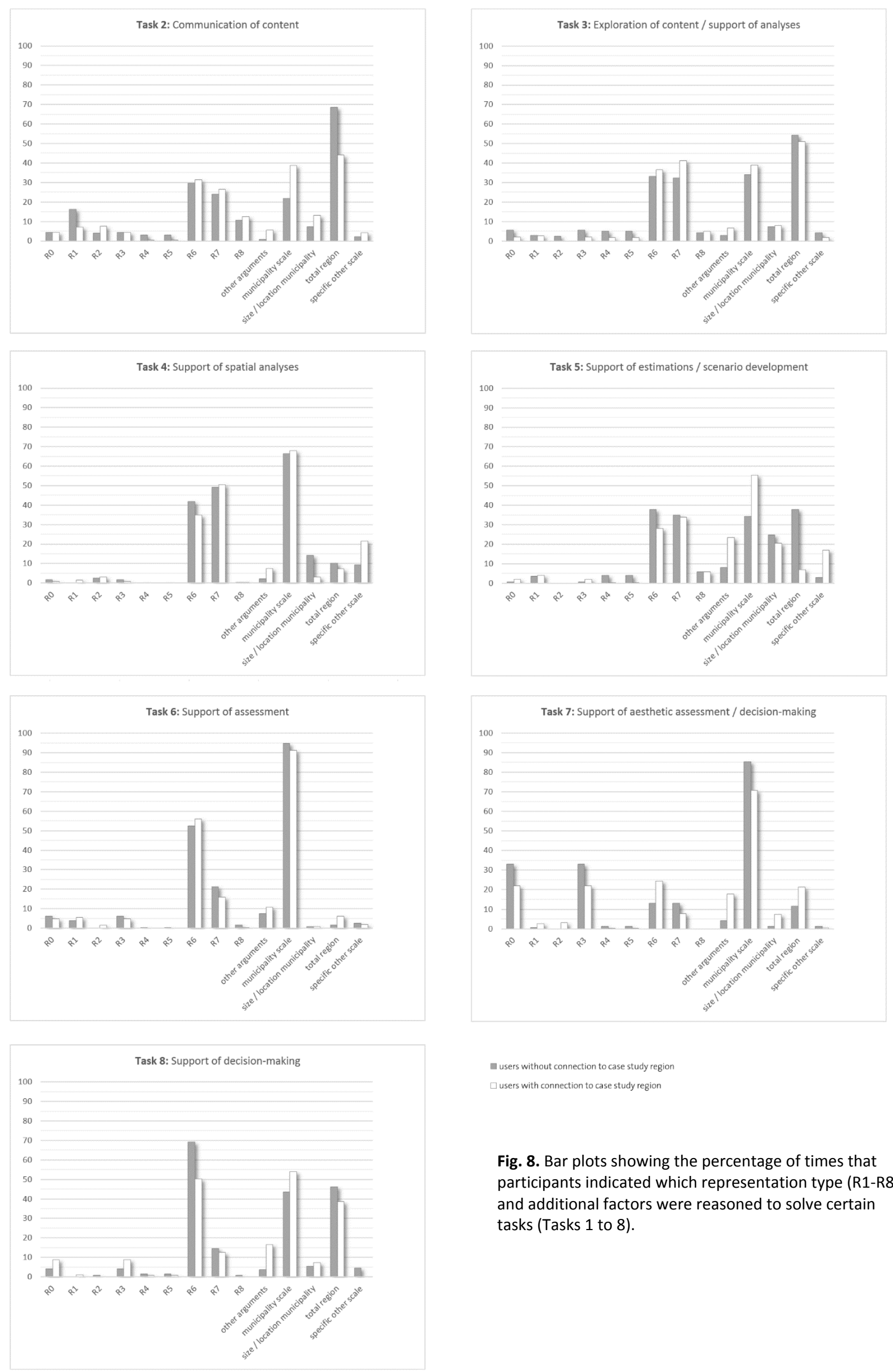

\footnotetext{
II users without connection to case study region

$\square$ users with connection to case study region
}

Fig. 8. Bar plots showing the percentage of times that participants indicated which representation type (R1-R8) and additional factors were reasoned to solve certain tasks (Tasks 1 to 8 ). 


\section{Discussion}

We found heterogeneous participant preferences for ES information presented in various types of representation. The specific demands for ES information to solve certain tasks-and therefore the ES information's function in application (Klein et al., 2015), as defined in our study-reflect the complexity of providing (decision) supportive information. However, a combination of various types of representation allowed the participants to customize the ES information in such a way that their personal preferences were met. This potentially led to a bias in using types of representation that were personally preferred but actually provided less supportive information for the task at hand. Participants may even have relied more heavily on less relevant information for decision-making because they chose the representation type based on its visual attractiveness instead of information relevance. Specific types of representation were preferred for certain tasks.

In particular, participant preferences for relying on types of certain ES information were context sensitive. Aspects that influenced participants' preferences and how they applied the available information included the topic of information, the reason why it was provided, the presented indicators and the details and scale of the information. Participants recognized situations in which needs and interests were not fully and clearly identified (e.g., Pettit et al., 2011; Bartke and Schwarze, 2015). If the ES information was not considered supportive, the participants ignored it for reasoning and decision-making. Instead, they relied on their experience and knowledge to bring in additional information that was not provided in the DSS. This effect was also described by Coussement et al. (2015); they concluded that a DSS that does not fully exploit all available information and neglects relevant information is unlikely to lead to optimal decisions. The authors also concluded that the opinions of experts, who are often the end participants in a DSS, must be heard during the design of the DSS to ensure that their needs are met. However, omission of information is not entirely inevitable and reflects the individuality of cognitive processes (Caspar et al., 1999). As our results show, there was no total individuality in the participants' cognitive processes. We identified differences between the participant groups and their reasoning as dependent on the participants' connection to the region. In addition, the availability of local knowledge seemed to affect decision-making. Participants with knowledge of the location based their rationales more on information not provided by the DSS, scales and even political issues, while using the ES information integrated in the DSS as a trigger to think or discuss about further impacts in the region. Natarajan (2015) emphasized the ways participants bring in this local knowledge for reasoning in participatory spatial planning. This reasoning of locals is often very detailed and explanatory based on personal experience (Natarajan, 2015). Thus, the cognitive processes and reasoning of the participants with a connection to the region were often more complex or included political rationales.

The visual complexity and therefore the reading, understanding and remembering of the information provided by the representation type also influenced its uses. Studies have shown that visual complexity and design influence participants' perception, preference and behavior (e.g., Machado et al., 2015; Quispel and Maes, 2014). In the present study, graphical information was used more than non-graphical information (for instance, text information). Although the text elements contained important information about the scenario, participants mostly ignored the text. With this behavior, scenario descriptions in R4 and R5 by DSS participants were ignored and therefore mostly not considered for reasoning, which shows that the participants were not able to weigh the importance of the information. This behavior likely was based on retrospection, which means that visual information, for example in charts, is easier to remember and to compare than text and numbers. Dilla and Raschke (2015) concluded that specifically graphical representations are more efficient and effective for spatial tasks (i.e., assessing relationships among data), while textual representations are more efficient and effective for symbolic tasks (i.e., extracting individual data values). Depending on the intention of the applied information, scaling, categorization and filtering of information clearly affect the frequency of use of a certain representation type. This behavior can be explained by cognitive cost-benefit theory, which poses that more efficient and effective decision-making results are accomplished when the problem representation matches the task (Vessey, 1991; Vessey and Galleta, 1991). Participants make compromises either in the complexity of reasoning or in the spatial scale of their reasoning, if the information does not entirely meet their demands. This behavior shows that DSS users are biased by the display scales of information. Thus, they find thinking on other scales or even "outside the box" by extrapolating or transferring information limited to municipalities and their characteristics to correlated indicators or dependent place specifications difficult. However, information about the region on a small display scale was used to analyze the proportions of the ES information by municipality in a larger scale context. For example, the participants struggled with the overall statements about the ES loss for the region, because this information was provided only by municipality, not in total for the region. Therefore, they reasoned only on a municipality scale about ES loss or instead used information provided on a regional scale. If they used other information for reasoning about ES loss, they often failed to infer and consequently link this information to ES, though. This behavior was also observed in the use of complex types of representation. If these types of representation comprised indicators that matched the information requirements for the specific task, they were used although they were more complicated to read. For example, the information about ES loss was, compared to the other types of representation, more difficult to read and to compare to the other information. Nevertheless, the participants employed this information because they had recognized its importance, and this was the only representation type that displayed the required information directly. Otherwise, if the participants did not want to refer to this representation type, they were forced to infer information about ES loss from other types of representation, which required a more complex cognitive process. Such user behavior supports Vessey's (1991) cognitive fit theory, which is a special case of the cognitive cost-benefit theory in which it specified that decision makers choose strategies that trade off the effort required to make a decision versus outcome accuracy (Beach and Mitchell, 1978; Payne, 1982).

The results showed that the participants used varying behaviors when they applied the ES information. These behaviors were mostly identified by the DSS participants with knowledge of the location. This local expertise led to alternative decision-making by using the information provided as a trigger while basing their reasoning on other information. 
Identifying or existing knowledge consequently influenced this decision-making strategy. Fig. 9 shows the decision-making model based on the results in combination with the cognitive fit and cognitive best-fit theories (Vessey, 1991; Vessey and Galleta, 1991) and alternative decision-making strategies. Depending on additional constraints (e.g., time pressure to accomplish a task/making a decision), the participants chose between accuracy-optimized and effort-optimized decisionmaking. It seems that users depended their type of decision-making on their expertise, difficulty of tasks, or knowledge where to find the relevant information in DSS. Due to these factors, users were potentially stressed (i.e. effort-optimized) because of limited time frame and choose the type of decision-making individually. However, if the provided information did not match the cognitive notion, the participants mostly tended to develop an alternative decision-making strategy (nonsolid arrow, Fig. 9). Finally, there was still the possibility that the participants did not want or were not able to make a decision due a lack of information, which led to inconclusiveness.

Providing additional supportive information could avoid precarious user reasoning and consequently support better decision-making. Although the amount of provided information may not be the critical factor in decision-making, an increase in information could influence the evaluation process (with more demand on time) and could therefore influence cognitive loops during decision-making (Jelokhani-Niaraki and Malczewski, 2014).

The amount of information in general influences a user's gaze. Results of other eye-tracking studies showed that fixation count and dwell time increased strongly with the number of AOIs (Vu et al., 2015; Horstmann et al., 2009; Lohse and Johnson, 1996; Reutskaja et al., 2011). In addition, the amount of information is a critical aspect that could lead to an overload of information in a DSS and consequently overstrain participants. In fact, it is unclear how the gaze data were biased in this study, because not all provided information was directly relevant or further used for reasoning. Additionally, time pressure (as was the case in this study) affects gaze behavior and therefore decision-making (Reutskaja et al., 2011). To avoid biased results through time pressure, we randomized the order of the tasks, and the AOIs were identical for all tasks. However, despite the unclear effects of time pressure, the results still show a diversity of participants' preferences in using ES information. The information provided did not change with the tasks, and Task 1 allow the participants to become acquainted with the information. 


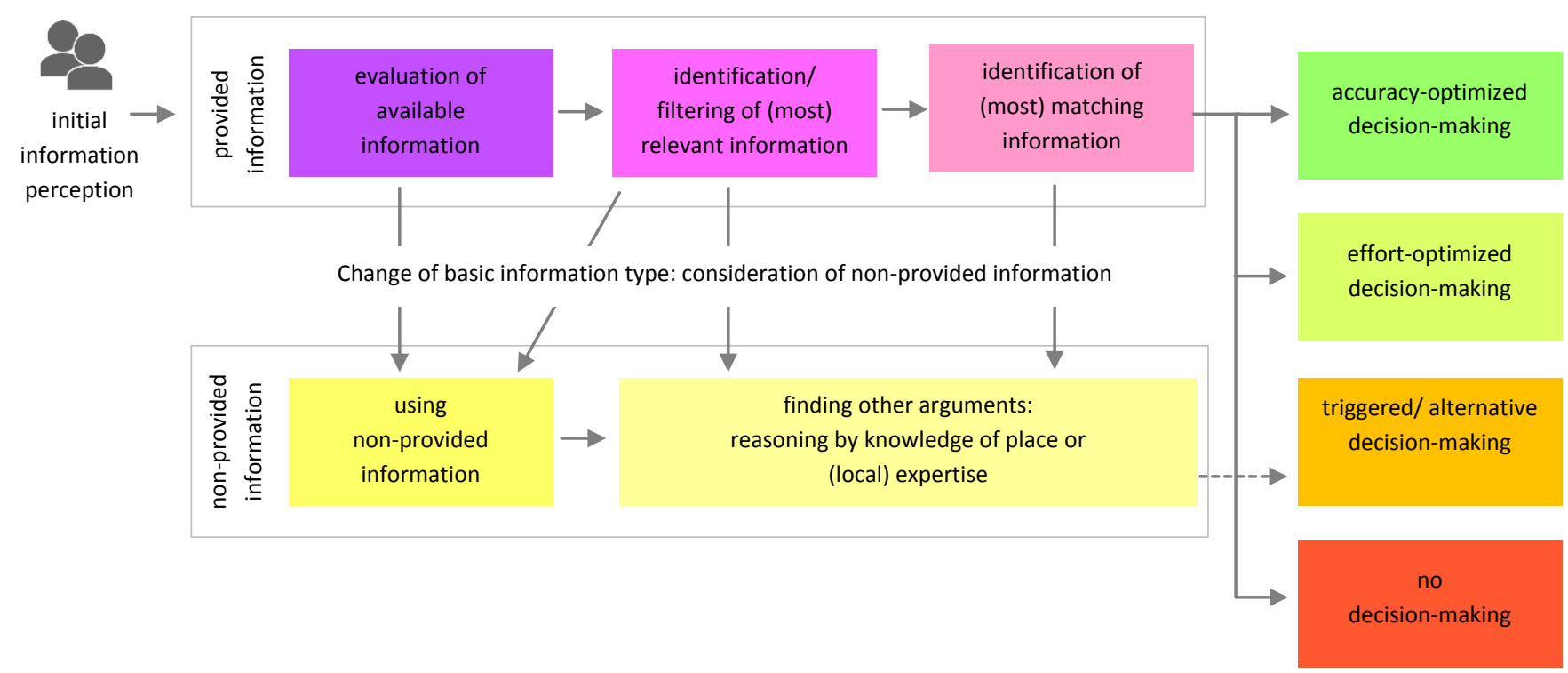

Fig. 9. Extended model of a representation-based decision-making process with alternatives strategies based on Vessey's (1991) and Vessey and Galleta's (1991) cognitive fit and cognitive best-fit theories, respectively.

The present study underlines the complexity of environmental communication and information provision. Especially for setting up a DSS, consideration of user demands is crucial, and relevant information must be integrated. For identifying and understanding these heterogeneous user demands and behaviors, requirement engineering approaches such as usability tests with ET are important and helpful (Klein et al., 2015). A demand analysis should be performed initially to identify userrelevant information, especially if there are heterogeneous user groups. Otherwise, DSS users are likely to ignore the provided information and not use it for reasoning. Instead, they use the provided information only as a trigger for accessing their own knowledge and experience and therefore do not work with the provided information. As a consequence, the DSS fails as a tool: Decisions are made without consideration of the provided information and are based solely on personal experiences and preferences. Consequently, there is a high risk that participants will be frustrated about the DSS or even ignore the provided information, because they cannot find common sense and reasons for common decision-making.

\section{Conclusions}

This study investigated user behaviors and cognitive processes while applying ES information integrated in a DSS. These results are information and user-group sensitive and do not necessarily support general statements about demands on ES information. Further, the results do not describe ES specific requirements. Instead, the study outlined the complexity of providing DSS and ES or environmental information as well as the relevance of user demands. The results of the ET approach show that the use of ES information by representation type depends on the intention of use. Further, cognitive processes varied among the participants. These results indicate the importance of multiple types of representation and the option of combining them to provide ES information.

Making general recommendations on how ES or environmental information should be represented and communicated is difficult. The information framework seems to be heavily context and user sensitive. In particular, the user behaviors and demands could vary among information content, region and reason or purpose why information is provided. This makes it challenging to meet all user demands. However, a good approach for covering such unpredictable user behaviors and demands is to provide a large set of types of representation that vary in visualization style, display type and scale. This allows users to filter and select the information they deem most supportive and relevant.

Furthermore, results show how the representation type characteristics of ES information influence the behaviors of users. Especially, detail and scale between applied information and reasoning is correlating, which describes the power of information provision and therefore the key for its operationalization. This could mean also in case of ES concept operationalization, tiered approaches are required as well as a variety of representing ES data to provide supportive information at different scales and for heterogeneous user groups.

\section{Acknowledgements}


This work is part of the 7th framework EU project "OPERAs-Operational Potential of Ecosystems Research Applications" (www.operas-project.eu; grant agreement number \#308393) and "OPSOL-Matching soil functions and soil uses in space and time for sustainable spatial development and land management - operationalizing cross-scale interactions in a virtual collaborative decision support system," which was funded by the Swiss National Science Foundation's National Research Program (NRP 68; www.nfp68.ch; grant agreement number \#406840_143092 / 1). We would like to offer special thanks to all study participants at HES and ETHZ for taking part and answering stressful questions, as well Mila Trombitas and Hildegard Loretan for their great support and organizational help at HES. The authors would like to thank the Institute of Cartography and Geoinformation (IKG, ETH) and Prof. Dr. Martin Raubal and his team members for providing the ET equipment and supported this work, especially Dr. Peter Kiefer and loannis Giannopoulos for their helpful feedback. Further, we would like to thank all PLUS team members who supported this study, especially Maarten van Strien. We would like to thank the anonymous reviewers for their valuable comments on the manuscript. 


\section{References}

Bartke, S., Schwarze, R., 2015. No perfect tools: trade-offs of sustainability principles and user requirements in designing support tools for land-use decisions between greenfields and brownfields. J. Environ. Manage. 153, 11-24.

Beach, L.R., Mitchell, F.R., 1978. A contingency model for the selection of decision strategies. Acad. Manage. Rev. 3, 439449.

BFS, 2015. Statistik Schweiz. Bundesamt für Statistik, Neuchâtel.

BLW, 2013. AGIS. Bundesamt für Landwirtschaft BLW, Bern.

BMUB, 2012. Bundesministerium für Umwelt, Naturzschutz, Bau und Reaktorsicherheit - Gesetz über den Zugang zu digitalen Geodaten (Geodatenzugangsgesetz - GeoZG). http://www.gesetze-iminternet.de/bundesrecht/geozg/gesamt.pdf, last access: 09.08.2015

Brändle, J.M., Langendijk, G., Peter, S., Brunner, S.H., Huber, R., 2015. Sensitivity analysis of a land-use change model with and without agents to assess land abandonment and long-term re-forestation in a Swiss mountain region. Land 4, 475512.

Brand, F.S., Seidl, R., Le, Q.B., Brändle, J., Scholz, R.W., 2013. Constructing consistent multiscale scenarios by transdisciplinary processes: the case of mountain regions facing global change. Ecol. Soc. 18 (2), 43.

Brömmelstroet, M., 2013. Performance of planning support systems. What is it, and how do we report on it? Comput. Environ. Urban 41, 299-308.

Campanelli, P., 1997. Testing survey questions: new directions in cognitive interviewing. Bulletin de Methodologie Sociologique, 55, 5-17.

Campanelli, P., Martin, E., Rothgeb, J.M., 1991. The use of respondent and interviewer debriefing studies as a way to study response error in survey data. Statistician 40, 253-264.

Cash, D.W., Clark, W.C., Alcock, N.M., Eckley, N., Guston, D.H., Jäger, J., Mitchell, R.B., 2003. Knowledge systems for sustainable development. PNAS 100 (14), 8086-8091.

Caspar, R.A., Lessler, J.T., Willis, G.B., 1999. Cognitive Interviewing - A “How To" Guide - Reducing Survey Error through Research on the Cognitive and Decision Processes in Surveys. Short course presented at the 1999 Meeting of the American Statistical Association.

Celio, E., Flint, C.G., Schoch, P., Grêt-Regamey, A., 2014. Farmers' perception of their decision-making in relation to policy schemes: a comparison of case studies from Switzerland and the United States. Land Use Policy 41, 163-171.

Coussement, K., Benoit, D.F., Antioco, M., 2015. A Bayesian approach for incorporating expert opinions into decision support systems: A case study of online consumer-satisfaction detection. Decis. Support Syst., accepted manuscript, 17 July 2015.

De Maio, T.J., Rothgeb, J.M., 1996. Cognitive interviewing techniques: In the lab and in the field. In: Schwarz, N., Sudman, S. (Eds.), Answering Questions: Methodology for Determining Cognitive and Communicative Processes in Survey Research. Jossey-Bass, San Francisco, pp. 177-195.

Dilla, W.N., Raschke, R.L., 2015. Data visualization for fraud detection: practice implications and a call for future research. Int. J. Acc. Inf. Syst. 16, 1-22.

Dippo, C., 1989. The use of cognitive laboratory techniques for investigating memory retrieval errors in retrospective surveys. Proceedings of the International Association of Survey Statisticians, International Statistical Institute, 323342.

Dixson, B.J., Grimshaw, G.M., Ormsby, D.K., Dixson, A.F., 2014. Eye-tracking women's preferences for men's somatotypes. Evol. Hum. Behav. 35, 73-79.

Duchowski, A.T., 2007. Eye Tracking Methodology - Theory and Practice. Springer, Berlin.

Dupont, L., Antrop, M., Van Eetvelde, V., 2013. Eye-tracking analysis in landscape perception research: influence of photograph properties and landscape characteristics. Landscape Res. 39, 417-432.

Esposito, J., Hess, J., 1992. The use of interviewer debriefings to identify problematic questions on alternative questionnaires. Paper presented at the annual meeting of the American Association for Public Opinion Research, St. Petersburg, FL.

European Commission, 2011. Factsheet to EU Biodiversity Strategy to 2020, December 2011. Available online: http://ec.europa.eu/environment/nature/info/pubs/docs/brochures/2020\%20Biod\%20brochure\%20final\%20lowres.p df, last access at 2014 December 15th.

European Commission, 2012. Our life insurance, our natural capital: an EU biodiversity strategy to 2020. European Parliament resolution of 20 April 2012 on our life insurance, our natural capital: an EU biodiversity strategy to 2020 (2011/2307(INI)). http://ec.europa.eu/environment/nature/biodiversity/comm2006/pdf/EP_resolution_april2012.pdf, last access: 09.08.2015

European Commission, 2015a. Broadband Strategy \& Policy. https://ec.europa.eu/digital-agenda/en/broadband-strategypolicy, last access: 09.08.2015

European Commission, 2015b. INSPIRE - Infrastructure for Spatial Information in the European Community. http://inspire.ec.europa.eu/, last access: 09.08.2015.

GeolG, 2007. Bundesgesetz über Geoinformation (Geoinformationsgesetz, GeolG). https://www.admin.ch/opc/de/officialcompilation/2008/2793.pdf, last access: 09.08.2015

Goldberg, J.H., Stimson, M.J., Lewenstein, M., Scott, N., Wichansky, A.M., 2002. Eye tracking in web search tasks: Design implications. Paper presented at the Eye Tracking Research and Applications Symposium, New Orleans, LA.

Grêt-Regamey, A., Celio, E., Klein, T.M., Wissen Hayek, U., 2013. Understanding ecosystem services trade-offs with interactive procedural modeling for sustainable urban planning. Landscape and Urban Planning, 109/1: 107-116. 
Höppner, C., Frick, J., Buchecker, M., 2007. Assessing psycho-social effects of participatory landscape planning. Landscape Urban Plan. 83, 196-207.

Holmqvist, K., Nyström, M., Andersson, R., Dewhurst, R., Jarodzka, H., Van de Weijer, J., 2011. Eye tracking: a comprehensive guide to methods and measures. Oxford, UK: Oxford University Press.

Horstmann, N., Ahlgrimm, A., Glöckner, A., 2009. How distinct are intuition and deliberation? An eye-tracking analysis of instruction-induced decision modes. Judgm. Decis. Mak. 4 (5), 335-354.

Jabine, T.B., Straf, M.L., Tanur, J.M., Tourangeau, R. (Eds.), 1984. Cognitive Aspects of Survey Methodology: Building a Bridge Between Disciplines. National Academy Press, Washington, DC.

Jacob, R., Karn, K., 2003. Eye tracking in human-computer interaction and usability research: ready to deliver the promises, in: Radach, R., Hyönä, J., Deubel, H. (Eds.), The Mind's Eye: Cognitive and Applied Aspects of Eye Movement Research. Elsevier, Amsterdam, pp. 573-605.

Jankowsky, P., Nyerges, T., 2001. Geographic Information Systems for Group Decision-Making: Towards A Participatory, Geographic Information Science. Taylor \& Francis, New York.

Jelokhani-Niaraki, M., Malczewski, J., 2014. The decision task complexity and information acquisition strategies in GISMCDA. Int. J. Geogr. Inf. Sci. 29 (2), 1-18.

Jelokhani-Niaraki, M., Malczewski, J., 2015. Decision complexity and consensus in Web-based spatial decision making: a case study of site selection problem using GIS and multicriteria analysis. Cities 45, 60-70.

Jobe, J.B., Mingay, D.J., 1991. Cognition and survey measurement: history and overview. Appl. Cognitive Psych. 5, 175-192.

Jobe, J.B., Tourangeau, R., Smith, A.F., 1993. Contributions of survey research to the understanding of memory. Appl. Cognitive Psychol. 7, 567-584.

Junker, B., Buchecker, M., 2008. Aesthetic preferences versus ecological objectives in river restorations. Landscape Urban Plan. 85, 141-154.

Keller, C.P., 1997. Unit 57 - Decision-making using multiple criteria. http://ibis.geog.ubc.ca/courses/klink/gis.notes/ncgia/u57.html\#SEC57.2.2; last access: 14.08.2014

Klein, T. M., Celio, E., Grêt-Regamey, A. (2015): Ecosystem services visualization and communication: A demand analysis approach for designing information and conceptualizing decision support systems. In: Ecosystem Services 13 (Special Issue: Best Practices for Mapping Ecosystem Services), p. 173-183

Lessler, J.T., Sirken, M.G., 1985. Laboratory-based research on the cognitive aspects of survey methodology: the goals and methods of the National Center for Health Statistics study. Health Soc. 63, 565-581.

Lohse, G.L., Johnson, E.J., 1996. A comparison of two process tracing methods for choice tasks. Organ. Behav. Hum. Dec. 68 (1), 28-43.

Machado, P., Romero, J., Nadal, M., Santos, A., Correia, J., Carballal, A., 2015. Computerized measures of visual complexity. Acta Psychologica 160, 43-57.

MESEU - Mapping of Ecosystems and their Services in the EU and its Member States, 2014. Synthesis report 2012-2014. October 31, 2014.

Mors, E.T., Weenig, M.W.H., Ellemers, N., Daamen, D.D.L., 2010. Effective communication about complex environmental issues: perceived quality of information about carbon dioxide capture and storage (CCS) depends on stakeholder collaboration. J. Environ. Psychol. 30, 347-357.

Natarajan, L., 2015. Socio-spatial learning: A case study of community knowledge in participatory spatial planning. Prog. Plann. doi:10.1016/j.progress.2015.06.002

Nivala, A.-M., Sarjakosk, L.T., Jakobsson, A., Kaasinen, E., 2001. Usability evaluation of topographic maps in mobile devices. Paper presented at the 20th International Cartographic Conference, Beijing, China.

Oh, K., Almarode, J.T., Tai, R.H., 2013. An exploration of think-aloud protocols linked with eye-gaze tracking: are they talking about what they are looking at. In: 3rd World Conference on Learning, Teaching and Educational Leadership WCLTA2012, Procedia - Social and Behavioral Sciences 93, 184-189.

Ooms, K., Coltekin, A., De Maeyer, P., Dupont, L., Fabrikant, S., Incoul, A., Vand der Haegen, L., 2014. Combining user logging with eye tracking for interactive and dynamic applications. Behaviour Research Methods: Epub ahead of print. doi:10.3758/s13428-014-0542-3

Payne, J.W., 1982. Contingent decision behavior. Psychol. Bull. 92 (2), 382-402.

Pettit, C.J., Raymond, C.M., Bryan, B.A., Lewis, H., 2011. Identifying strengths and weaknesses of landscape visualization for effective communication of future alternatives. Landscape Urban Plan. 100, 231-241.

Pieters, R., 2008. A review of eye-tracking research in marketing. Rev. Marketing Res. 4, 123-147.

Pieters, R., Wedel, M., 2004. Attention capture and transfer in advertising: brand, pictorial, and text-size effects. J. Marketing 68, 36-50.

Poole, A., Ball, L.J., 2006. Eye tracking in human computer interaction and usability research: current status and future prospects. In: Ghaoui, C. (Ed.), Encyclopedia of Human Computer Interaction, Idea Group, Hershey, pp. 211-219.

Quispel, A., Maes, A., 2014. Would you prefer pie or cupcakes? Preferences for data visualization designs of professionals and laypeople in graphic design. J. Visual Lang. Comput. 25, 107-116.

Rayner, K., 1998. Eye movement in reading and information processing: 20 years of research. Psychol. Bull. 124, 372-422.

Rayner, K., 2009. Eye movements and attention in reading, scene perception, and visual search. J. Exp. Psychol. 62, 14571506

Recarte, M.A., Nunes, L.M., 2000. Effects of verbal and spatialimagery tasks on eye fixations while driving. J. Exp. Psychol.Appl. 6, 31-43.

Reutskaja, E., Nagel, R., Camerer, C.F., Rangel, A., 2011. Search dynamics in consumer choice under time pressure: an eyetracking study. Am. Econ. Rev. 101 (2), 900-926. 
Rogge, E., Dessein, J., Gulinck, H., 2011. Stakeholders perception of attitudes towards major landscape changes held by the public: the case of greenhouse clusters in Flanders. Land Use Policy 28, 334-342.

Royston, P., Bercini, D., Sirken, M., Mingay, D., 1986. Questionnaire Design Research Laboratory. Proceedings of the Section on Survey Methods Research, American Statistical Association, 703-707.

Ruckelshaus, M., McKenzie, E., Tallis, H., Guerry, A., Daily, G., Kareiva, P., Polasky, S., Ricketts, T., Bhagabati, N., Wood, S. A., Bernhardt, J., 2015. Notes from the field: lessons learned from using ecosystem services approaches to inform readworld decision. Ecol. Econ. 115, 11-21.

Russo, P., Pettit, C., Coltekin, A., Imhof, M., Cox, M., Bayliss, C., 2014. Understanding soil acidification process using animation and text: an empirical user evaluation with eye tracking, in: Cartography from Polo to Pole - Lecture Notes in Geoinformation and Cartography. Springer-Verlag Berlin, pp. 431-448.

Sirken, M.G., Herrmann, M.G., Schechter, S., Schwarz, N., Tanur, J.M., Tourangeau, R., 1999. Cognition and Survey Research. Wiley, New York.

Simon, H.A., 1960. The New Science of Management Decisions. Prentice-Hall, Englewood Cliffs.

Sugumaran, R., De Groote, J., 2011. Spatial Decision Support Systems - Principles and Practices. CRC Press, Boca Raton.

Veríssimo, D., Campbell, B., 2015. Understanding stakeholder conflict between conservation and hunting in Malta. Biol. Conserv., article in press.

Vessey, I., 1991. Cognitive fit: a theory based analysis of the graphs versus tables literature. Decision Sci. 22 (2), $219-241$.

Vessey, I., Galletta, D., 1991. Cognitive fit: an empirical study of information acquisition. Inf. Syst. Res. 2 (1), 63-84.

Vidal, L., Antúnez, L., Sapolinski, A., Giménez, A., Maiche, A., Ares, G., 2013. Can eye-tracking techniques overcome a limitation of conjoint analysis? Case study on healthfulness perception of yogurt labels. J. Sens. Studies 28, 370-380.

Visp, 2015. History of Visp. 2015 [cited 2015 April 8th]; Available from: http://www.visp.ch/portraet/geschichtliches.php.

VSGIS, 2015. Kantonales GIS des Kanton Wallis.

Vu, T.M.H., Tu, V.P., Duerrschmid, K., 2015. Design factors influence consumers' gazing behaviour and decision time in an eye-tracking test: A study on food images. Food Qual. Prefer., article in press.

Willis, G.B., 2005. Cognitive Interviewing. A Tool for Improving Questionnaire Design. Sage, Thousand Oaks.

Willis, G., DeMaio, T., Harris-Kojetin, B., 1999. Is the bandwagon headed to the methodological promised land? Evaluation of the validity of cognitive interviewing techniques, in: Sirken, M., Herrmann, D., Schechter, S., Schwarz, N., Tanur, J., Tourangeau, R. (Eds.), Cognition and Survey Research, Wiley, New York, pp. xxx-xxx.

Willis, G.B., Schechter, S., 1997. Evaluation of cognitive interviewing techniques: do the results generalize to the field? Bulletin de Methodologie Sociologique 55, 40-66.

Willson, S., Miller, K., 2014. Data collection, in: Miller, K., Willson, S., Chepp, V., Padilla, J.-L. (Eds.), Cognitive Interviewing Methodology. Wiley, pp. 15-33.

Wissen Hayek, U., Teich, M., Klein, T. M., Grêt-Regamey, A., 2015. Bringing ecosystem services indicators into spatial planning practice: Lessons from collaborative development of a web-based visualization platform. Ecol. Indic., available online: doi:10.1016/j.ecolind.2015.03.035 


\section{APPENDICES}

\section{Table A1}

Overview of the types of representation (AOIs) with their characteristics (AOI coverage in DSS, interactive functionality), and information content.

\begin{tabular}{|c|c|c|c|c|c|}
\hline (AOI) & Representation type & Information & $\begin{array}{l}\text { Interac } \\
\text { tive }\end{array}$ & $\begin{array}{l}\text { Time } \\
\text { series* }\end{array}$ & $\begin{array}{c}\text { AOI } \\
\text { coverage** }\end{array}$ \\
\hline RO & $\begin{array}{l}\text { Realistic landscape } \\
\text { visualization }\end{array}$ & $\begin{array}{l}\text { Landscape scenery of municipality of Visp } \\
\text { that shows a settlement area in } 2034\end{array}$ & no & no & $7.4 \%$ \\
\hline R1 & Pie and bar chart & $\begin{array}{l}\text { Land-use information for study region with } \\
\text { additional time behavior for 2014, 2019, } \\
\text { 2024, 2029, } 2034\end{array}$ & yes & yes & $9.3 \%$ \\
\hline $\mathrm{R} 2$ & Thematic 2D map & $\begin{array}{l}\text { Land-use information for study region in } \\
2034\end{array}$ & yes & no & $11.9 \%$ \\
\hline R3 & $\begin{array}{l}\text { Photo-realistic } \\
\text { landscape visualization }\end{array}$ & $\begin{array}{l}\text { Landscape scenery of municipality of Saas- } \\
\text { Fee that shows a settlement area in } 2034\end{array}$ & no & no & $10.6 \%$ \\
\hline R4 & Text/abstract & $\begin{array}{l}\text { Short abstract about scenario preconditions } \\
\text { and the general behavior }\end{array}$ & no & no & $3.5 \%$ \\
\hline R5 & Icons & Scenario preconditions & yes & no & $1.0 \%$ \\
\hline R6 & Stacked bar chart & $\begin{array}{l}\text { Potential of ecosystem services loss for each } \\
\text { municipality in } 2034\end{array}$ & no & no & $10.6 \%$ \\
\hline R7 & Stacked bar chart & $\begin{array}{l}\text { Settlement area in } 2014 \text { and } 2034 \text { for each } \\
\text { municipality }\end{array}$ & no & yes & $10.0 \%$ \\
\hline R8 & Grouped bar chart & $\begin{array}{l}\text { Total agricultural production with the food } \\
\text { products milk, meat and crop for 2014, 2019, } \\
2024,2029,2034\end{array}$ & no & yes & $10.0 \%$ \\
\hline
\end{tabular}

* Information is provided for multiple years

** $\quad 25.80 \%$ of DSS coverage consist of background, task information, button to switch between scenarios, institute icons that was measured as "white space" and was not further considered in the analysis 


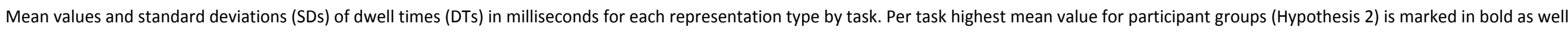
the three most used types of representation in total. Highlighted colors for types of representation correspond to the AOIs.

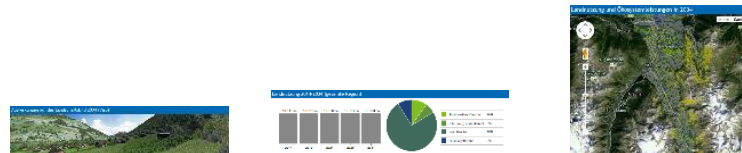

Ro
R1
R2

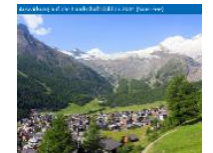

R3

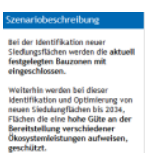

R4

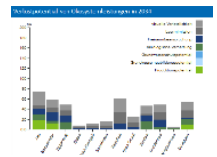

R6

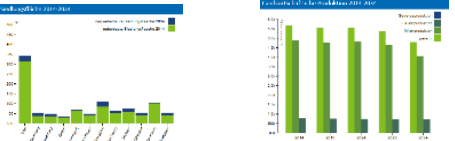

R7
R8

\begin{tabular}{|c|c|c|c|c|c|c|c|c|c|c|c|c|c|c|c|c|c|c|c|}
\hline Task & Region* & Mean & SD & Mean & SD & Mean & SD & Mean & SD & Mean & SD & Mean & SD & Mean & SD & Mean & SD & Mean & SD \\
\hline \multirow{3}{*}{2} & no & 3.255 & 2.966 & 12.939 & 11.225 & 7.615 & 6.280 & 4.493 & 4.023 & 4.318 & 6.510 & 1.728 & 3.168 & 22.107 & 12.263 & 15.907 & 7.633 & 10.189 & 6.830 \\
\hline & yes & 3.722 & 4.746 & 8.961 & 8.201 & 9.518 & 9.844 & 6.039 & 7.095 & 1.751 & 3.224 & 488 & 1.256 & 16.989 & 10.437 & 17.553 & 10.638 & 12.710 & 9.338 \\
\hline & total & 3.493 & 3.962 & 10.911 & 9.954 & 8.585 & 8.306 & 5.281 & 5.820 & 3.009 & 5.241 & 1.096 & 2.461 & $19.498^{1}$ & 11.600 & $16.746^{2}$ & 9.279 & $11.475^{3}$ & 8.263 \\
\hline \multirow{3}{*}{3} & no & 3.538 & 3.260 & 12.344 & 12.125 & 9.698 & 9.861 & 2.977 & 2.929 & 8.833 & 15.361 & 5.564 & 8.797 & 18.748 & 14.268 & 14.570 & 7.842 & 7.173 & 6.038 \\
\hline & yes & 4.615 & 8.080 & 9.340 & 10.282 & 8.905 & 9.380 & 5.204 & 8.054 & 3.583 & 8.717 & 1.829 & 4.037 & 17.650 & 12.522 & 16.968 & 11.528 & 6.879 & 6.533 \\
\hline & total & 4.087 & 6.198 & $10.812^{3}$ & 11.269 & 9.293 & 9.579 & 4.113 & 6.178 & 6.156 & 12.641 & 3.660 & 7.021 & $18.189^{1}$ & 13.351 & $15.793^{2}$ & 9.919 & 7.023 & 6.266 \\
\hline \multirow{3}{*}{4} & no & 4.941 & 8.173 & 5.188 & 7.674 & 36.034 & 28.843 & 3.766 & 5.000 & 1.107 & 3.012 & 966 & 2.747 & 19.137 & 16.658 & 16.900 & 15.457 & 2.728 & 3.982 \\
\hline & yes & 4.170 & 7.778 & 6.581 & 8.301 & 20.965 & 25.176 & 3.799 & 6.074 & 1.252 & 3.912 & 482 & 1.413 & 21.562 & 20.986 & 20.901 & 17.982 & 3.047 & 3.646 \\
\hline & total & 4.548 & 7.944 & 5.898 & 7.991 & $28.352^{1}$ & 27.946 & 3.783 & 5.546 & 1.181 & 3.484 & 720 & 2.174 & $20.373^{2}$ & 18.934 & $18.940^{3}$ & 16.830 & 2.891 & 3.799 \\
\hline \multirow{3}{*}{5} & no & 4.872 & 5.690 & 7.215 & 8.337 & 12.639 & 14.361 & 3.297 & 4.057 & 4.296 & 7.632 & 2.358 & 4.121 & 20.857 & 12.593 & 20.435 & 12.495 & 4.762 & 5.191 \\
\hline & yes & 4.679 & 5.043 & 9.553 & 10.921 & 13.381 & 15.985 & 4.169 & 7.680 & 2.765 & 4.312 & 1.834 & 3.647 & 17.961 & 12.559 & 15.401 & 9.773 & 5.817 & 5.587 \\
\hline & total & 4.773 & 5.344 & 8.407 & 9.764 & $13.017^{3}$ & 15.140 & 3.741 & 6.161 & 3.516 & 6.184 & 2.091 & 3.876 & $19.380^{1}$ & 12.597 & $17.869^{2}$ & 11.418 & 5.300 & 5.396 \\
\hline \multirow{3}{*}{6} & no & 6.827 & 9.982 & 5.303 & 8.478 & 14.608 & 17.498 & 6.447 & 7.417 & 3.283 & 7.134 & 1.633 & 4.488 & 32.432 & 19.294 & 13.178 & 10.210 & 2.774 & 3.512 \\
\hline & yes & 3.374 & 4.570 & 7.369 & 8.292 & 6.503 & 7.934 & 3.970 & 4.959 & 2.521 & 6.782 & 1.142 & 2.112 & 33.722 & 20.730 & 13.203 & 8.599 & 4.431 & 4.621 \\
\hline & total & 5.067 & 7.867 & 6.356 & 8.406 & $10.476^{3}$ & 14.032 & 5.184 & 6.377 & 2.895 & 6.933 & 1.383 & 3.476 & $33.090^{1}$ & 19.950 & $13.191^{2}$ & 9.376 & 3.618 & 4.178 \\
\hline \multirow{3}{*}{7} & no & 17.492 & 11.275 & 8.062 & 10.361 & 15.654 & 15.485 & 17.136 & 11.339 & 2.910 & 5.202 & 2.321 & 4.663 & 13.819 & 15.708 & 5.670 & 5.937 & 3.286 & 3.720 \\
\hline & yes & 17.663 & 16.337 & 6.539 & 6.860 & 17.570 & 16.419 & 13.957 & 10.871 & 1.497 & 3.841 & 1.296 & 2.907 & 10.465 & 12.262 & 6.492 & 6.342 & 3.386 & 4.169 \\
\hline & total & $17.579^{1}$ & 14.016 & 7.286 & 8.742 & $16.631^{2}$ & 15.918 & $15.515^{3}$ & 11.162 & 2.190 & 4.591 & 1.799 & 3.883 & 12.109 & 14.088 & 6.089 & 6.130 & 3.337 & 3.936 \\
\hline & no & 2.406 & 1.751 & 14.764 & 12.446 & 9.262 & 10.344 & 2.228 & 2.291 & 4.314 & 8.216 & 2.979 & 5.923 & 39.227 & 23.291 & 7.451 & 5.144 & 5.312 & 5.373 \\
\hline 8 & yes & 3.799 & 5.233 & 12.257 & 10.276 & 8.013 & 8.699 & 4.388 & 4.797 & 3.264 & 7.328 & 1.736 & 3.077 & 30.351 & 18.858 & 8.640 & 7.445 & 6.731 & 6.070 \\
\hline
\end{tabular}


* between-subjects factor variable: participants' relation to the region (Hypothesis 2 )

${ }^{1}=$ type of representation with the longest dwell time, ${ }^{2}=$ type of representation with the second longest dwell time, ${ }^{3}=$ type of representation with the third longest dwell time

\section{Table A3}

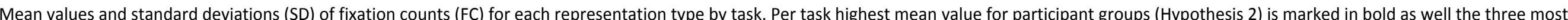
used types of representation in total. Highlighted colors for types of representation correspond to the AOIs.

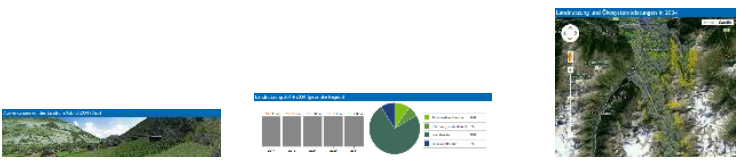

Ro
R1

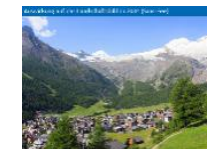

R3

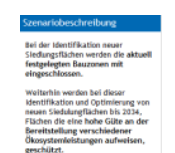

R4

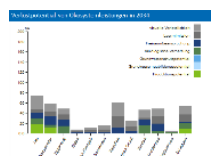

R6

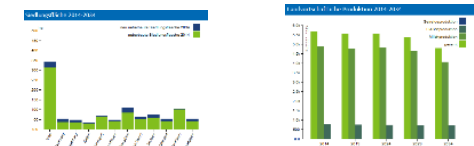

R7
R8

\begin{tabular}{|c|c|c|c|c|c|c|c|c|c|c|c|c|c|c|c|c|c|c|c|}
\hline Task & Region* & Mean & SD & Mean & SD & Mean & SD & Mean & SD & Mean & SD & Mean & SD & Mean & SD & Mean & SD & Mean & SD \\
\hline \multirow{2}{*}{2} & no & 13,50 & 11,77 & 47,14 & 37,57 & 29,86 & 22,56 & 18,02 & 14,59 & 16,82 & 23,11 & 6,18 & 9,72 & 83,54 & 41,25 & 63,24 & 27,03 & 41,12 & 26,13 \\
\hline & yes & 15,92 & 18,36 & 35,77 & 29,38 & 39,19 & 36,75 & 25,00 & 26,15 & 7,35 & 12,67 & 2,21 & 5,45 & 68,50 & 40,22 & 72,02 & 39,97 & 53,08 & 34,63 \\
\hline \multirow[b]{2}{*}{3} & no & 13,14 & 11,06 & 42,74 & 38,91 & 30,06 & 27,32 & 9,86 & 8,68 & 32,80 & 56,64 & 19,48 & 29,68 & 69,02 & 47,12 & 53,62 & 27,16 & 26,16 & 17,53 \\
\hline & yes & 17,44 & 24,60 & 34,58 & 32,74 & 32,88 & 29,51 & 18,54 & 24,78 & 14,44 & 33,96 & 7,50 & 14,71 & 70,17 & 45,18 & 66,87 & 41,61 & 27,69 & 23,75 \\
\hline \multirow{3}{*}{4} & no & 17,28 & 24,54 & 18,80 & 25,93 & 107,54 & 84,17 & 11,96 & 14,70 & 4,60 & 12,67 & 2,98 & 8,93 & 65,36 & 51,18 & 59,54 & 51,60 & 11,20 & 15,49 \\
\hline & yes & 16,42 & 27,18 & 24,12 & 28,17 & 71,79 & 77,95 & 14,87 & 22,26 & 5,33 & 15,41 & 2,02 & 5,78 & 79,19 & 70,97 & 78,63 & 61,70 & 12,92 & 15,03 \\
\hline & total & 16,84 & 25,79 & 21,51 & 27,10 & $89,31^{1}$ & 82,63 & 13,44 & 18,90 & 4,97 & 14,07 & 2,49 & 7,47 & $72,41^{2}$ & 62,15 & $69,27^{3}$ & 57,50 & 12,08 & 15,21 \\
\hline \multirow{3}{*}{5} & no & 15,82 & 16,90 & 26,06 & 24,90 & 40,28 & 43,51 & 10,36 & 10,79 & 16,72 & 29,84 & 8,96 & 15,16 & 76,22 & 42,96 & 74,18 & 40,81 & 18,86 & 18,08 \\
\hline & yes & 18,21 & 19,02 & 35,63 & 36,66 & 48,15 & 51,00 & 14,98 & 22,77 & 11,33 & 17,28 & 7,15 & 13,57 & 69,65 & 45,04 & 61,12 & 33,74 & 25,71 & 22,50 \\
\hline & total & 17,04 & 17,96 & 30,94 & 31,66 & $44,29^{3}$ & 47,41 & 12,72 & 17,99 & 13,97 & 24,29 & 8,04 & 14,33 & $72,87^{1}$ & 43,94 & $67,52^{2}$ & 37,76 & 22,35 & 20,64 \\
\hline \multirow{3}{*}{6} & no & 19,66 & 24,33 & 19,32 & 27,39 & 43,92 & 47,34 & 18,50 & 17,13 & 13,04 & 28,14 & 5,76 & 13,28 & 112,02 & 62,49 & 47,82 & 33,79 & 11,86 & 14,40 \\
\hline & yes & 13,50 & 16,47 & 28,87 & 29,04 & 25,10 & 26,90 & 15,17 & 17,74 & 10,52 & 27,74 & 5,02 & 9,11 & 126,06 & 65,56 & 53,08 & 29,55 & 18,83 & 18,39 \\
\hline & total & 16,52 & 20,83 & 24,19 & 28,51 & $34,32^{3}$ & 39,27 & 16,80 & 17,44 & 11,75 & 27,83 & 5,38 & 11,30 & $119,18^{1}$ & 64,14 & $50,50^{2}$ & 31,65 & 15,41 & 16,84 \\
\hline \multirow{2}{*}{7} & no & 55,82 & 34,97 & 28,84 & 34,85 & 47,26 & 39,62 & 49,66 & 36,32 & 11,86 & 20,45 & 8,18 & 15,85 & 48,66 & 46,01 & 22,72 & 20,33 & 13,52 & 14,06 \\
\hline & yes & 60,79 & 47,05 & 26,27 & 25,61 & 60,63 & 50,83 & 46,40 & 32,71 & 6,25 & 14,93 & 5,25 & 11,54 & 43,15 & 48,67 & 26,35 & 23,94 & 14,65 & 16,83 \\
\hline
\end{tabular}




\begin{tabular}{|c|c|c|c|c|c|c|c|c|c|c|c|c|c|c|c|c|c|c|c|}
\hline & total & $58,35^{1}$ & 41,44 & 27,53 & 30,37 & $54,08^{2}$ & 45,95 & $48,00^{3}$ & 34,39 & 9,00 & 17,98 & 6,69 & 13,83 & 45,85 & 47,23 & 24,57 & 22,21 & 14,10 & 15,47 \\
\hline \multirow{3}{*}{8} & no & 9,28 & 6,22 & 49,68 & 39,89 & 31,16 & 33,44 & 7,58 & 6,97 & 16,54 & 30,38 & 9,94 & 17,37 & 133,00 & 68,60 & 29,64 & 18,76 & 19,24 & 18,06 \\
\hline & yes & 14,73 & 18,63 & 44,79 & 34,95 & 30,27 & 31,17 & 16,25 & 15,63 & 13,73 & 29,38 & 7,44 & 12,39 & 117,50 & 71,93 & 34,46 & 27,22 & 26,69 & 23,36 \\
\hline & total & 12,06 & 14,20 & $47,19^{2}$ & 37,35 & 30,71 & 32,14 & 12,00 & 12,88 & 15,11 & 29,76 & 8,67 & 15,02 & $125,10^{1}$ & 70,40 & $32,10^{3}$ & 23,47 & 23,04 & 21,16 \\
\hline
\end{tabular}

* between-subjects factor variable: participants' relation to the region (Hypothesis 2)

${ }^{1}=$ most fixated representation type, ${ }^{2}=$ second most fixated representation type, ${ }^{3}=$ third most fixated representation type

\section{Table A4}

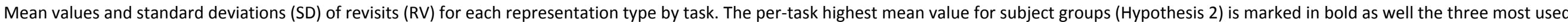
types of representation in total. Highlighted colors for types of representation correspond to the AOIs.

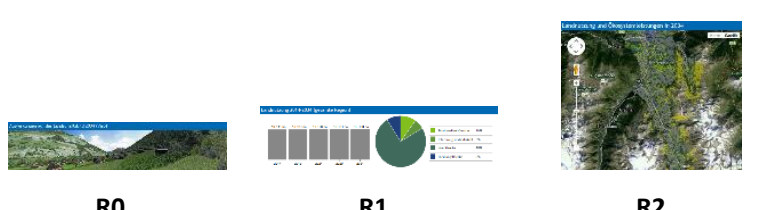

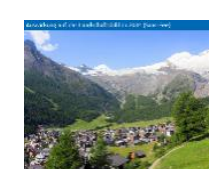

R3

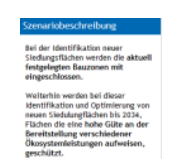

R4

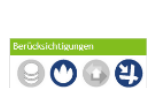

R5

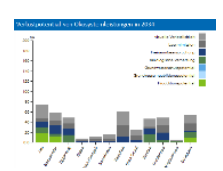

R6

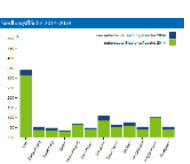

R7

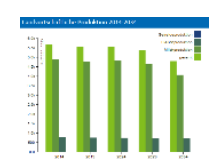

$\mathbf{R 8}$

\begin{tabular}{|c|c|c|c|c|c|c|c|c|c|c|c|c|c|c|c|c|c|c|c|}
\hline Task & Region* & Mean & SD & Mean & SD & Mean & SD & Mean & SD & Mean & SD & Mean & SD & Mean & SD & Mean & SD & Mean & SD \\
\hline \multirow{3}{*}{2} & no & 3,64 & 3,38 & 5,86 & 4,47 & 7,34 & 5,79 & 4,28 & 2,96 & 1,74 & 2,08 & 0,92 & 1,38 & 10,78 & 6,66 & 11,22 & 6,01 & 5,78 & 3,32 \\
\hline & yes & 3,23 & 3,60 & 5,29 & 3,89 & 9,02 & 6,72 & 5,13 & 5,23 & 1,25 & 2,09 & 0,35 & 0,81 & 8,44 & 5,85 & 11,04 & 6,64 & 6,52 & 3,63 \\
\hline & total & 3,43 & 3,48 & 5,57 & 4,17 & $8,20^{3}$ & 6,31 & 4,72 & 4,27 & 1,49 & 2,09 & 0,63 & 1,16 & $9,59^{2}$ & 6,34 & $11,13^{1}$ & 6,31 & 6,16 & 3,49 \\
\hline \multirow{3}{*}{3} & no & 3,48 & 2,75 & 6,00 & 3,52 & 6,20 & 3,30 & 2,46 & 2,10 & 3,10 & 4,67 & 3,04 & 4,74 & 11,64 & 7,06 & 12,12 & 7,27 & 4,46 & 2,77 \\
\hline & yes & 4,23 & 3,57 & 5,29 & 3,76 & 7,67 & 5,48 & 3,87 & 4,03 & 1,60 & 2,93 & 1,42 & 3,18 & 12,31 & 7,34 & 13,73 & 7,45 & 4,85 & 3,89 \\
\hline & total & 3,86 & 3,20 & 5,64 & 3,64 & $6,95^{3}$ & 4,58 & 3,18 & 3,29 & 2,33 & 3,93 & 2,22 & 4,08 & $11,98^{2}$ & 7,18 & $12,94^{1}$ & 7,37 & 4,66 & 3,38 \\
\hline \multirow{3}{*}{4} & no & 3,30 & 3,79 & 3,84 & 5,04 & 8,96 & 5,02 & 2,40 & 2,73 & 0,54 & 1,20 & 0,38 & 1,34 & 10,24 & 7,65 & 10,32 & 8,49 & 2,30 & 2,90 \\
\hline & yes & 3,15 & 3,59 & 3,81 & 4,32 & 7,77 & 6,19 & 3,15 & 4,12 & 0,69 & 1,38 & 0,33 & 0,88 & 9,56 & 6,62 & 11,21 & 6,51 & 2,85 & 3,70 \\
\hline & total & 3,23 & 3,67 & 3,82 & 4,66 & $8,35^{3}$ & 5,65 & 2,78 & 3,51 & 0,62 & 1,29 & 0,35 & 1,12 & $9,89^{2}$ & 7,12 & $10,77^{1}$ & 7,52 & 2,58 & 3,33 \\
\hline \multirow{3}{*}{5} & no & 4,20 & 4,18 & 5,28 & 3,93 & 7,64 & 5,07 & 2,62 & 3,06 & 2,52 & 4,98 & 1,88 & 3,74 & 13,40 & 8,36 & 15,26 & 8,59 & 4,12 & 4,16 \\
\hline & yes & 3,60 & 3,55 & 5,17 & 4,02 & 8,35 & 5,53 & 3,31 & 3,65 & 0,79 & 1,16 & 1,13 & 2,47 & 11,17 & 6,43 & 12,29 & 7,00 & 4,96 & 3,59 \\
\hline & total & 3,89 & 3,87 & 5,23 & 3,96 & $8,00^{3}$ & 5,30 & 2,97 & 3,38 & 1,64 & 3,67 & 1,50 & 3,16 & $12,26^{2}$ & 7,48 & $13,75^{1}$ & 7,92 & 4,55 & 3,88 \\
\hline \multirow{2}{*}{6} & no & 3,24 & 3,08 & 3,26 & 3,06 & 6,00 & 4,80 & 3,64 & 3,39 & 1,32 & 2,64 & 0,90 & 1,80 & 12,24 & 7,28 & 10,78 & 6,91 & 2,50 & 2,60 \\
\hline & yes & 2,92 & 3,20 & 4,38 & 3,86 & 5,46 & 5,01 & 3,06 & 3,44 & 1,08 & 2,50 & 1,04 & 2,34 & 13,31 & 8,39 & 11,33 & 6,93 & 3,29 & 2,91 \\
\hline
\end{tabular}




\begin{tabular}{|c|c|c|c|c|c|c|c|c|c|c|c|c|c|c|c|c|c|c|c|}
\hline & total & 3,08 & 3,13 & 3,83 & 3,52 & $5,73^{3}$ & 4,89 & 3,34 & 3,41 & 1,20 & 2,56 & 0,97 & 2,08 & $12,78^{1}$ & 7,85 & $11,06^{2}$ & 6,89 & 2,90 & 2,78 \\
\hline \multirow{3}{*}{7} & no & 9,86 & 5,23 & 4,82 & 4,94 & 8,96 & 5,33 & 7,88 & 5,18 & 1,34 & 2,20 & 1,18 & 1,66 & 7,94 & 5,27 & 6,04 & 4,48 & 2,88 & 2,86 \\
\hline & yes & 9,60 & 5,18 & 5,31 & 4,30 & 9,35 & 4,61 & 8,44 & 4,68 & 0,73 & 1,60 & 0,63 & 1,51 & 7,48 & 6,16 & 6,25 & 5,11 & 2,92 & 2,90 \\
\hline & total & $9,73^{1}$ & 5,18 & 5,07 & 4,61 & $9,16^{2}$ & 4,95 & $8,17^{3}$ & 4,91 & 1,03 & 1,93 & 0,90 & 1,60 & 7,71 & 5,72 & 6,15 & 4,79 & 2,90 & 2,86 \\
\hline \multirow{3}{*}{8} & no & 2,66 & 2,17 & 5,72 & 4,67 & 5,10 & 3,54 & 1,92 & 1,96 & 1,68 & 2,58 & 1,44 & 2,42 & 12,12 & 5,63 & 6,98 & 3,58 & 3,02 & 2,43 \\
\hline & yes & 3,79 & 3,24 & 6,23 & 4,34 & 5,73 & 4,48 & 4,00 & 3,42 & 1,52 & 2,28 & 1,25 & 2,09 & 12,46 & 6,32 & 8,12 & 5,58 & 4,08 & 2,64 \\
\hline & total & 3,24 & 2,82 & $5,98^{3}$ & 4,49 & 5,42 & 4,04 & 2,98 & 2,98 & 1,60 & 2,42 & 1,34 & 2,25 & $12,29^{1}$ & 5,96 & $7,56^{2}$ & 4,72 & 3,56 & 2,58 \\
\hline
\end{tabular}

* between-subjects factor variable: participants' relation to the region (Hypothesis 2)

${ }^{1}=$ most revisited representation type, ${ }^{2}=$ second most revisited representation type, ${ }^{3}=$ third most revisited representation type 
Table A5

Estimated ET variable measures.

95\% Confidence Interval

\begin{tabular}{|c|c|c|c|c|c|}
\hline & & Mean & Std. Error & Lower Bound & Upper Bound \\
\hline \multirow[t]{9}{*}{ Dwell Time (DT) } & RO & 6096,658 & 415,118 & 5273,076 & 6920,240 \\
\hline & R1 & 9029,566 & 391,375 & 8253,088 & 9806,043 \\
\hline & $\mathrm{R} 2$ & 13597,474 & 764,503 & 12080,721 & 15114,226 \\
\hline & R3 & 5847,798 & 364,093 & 5125,448 & 6570,148 \\
\hline & R4 & 3263,900 & 407,929 & 2454,580 & 4073,220 \\
\hline & R5 & 1882,673 & 223,079 & 1440,091 & 2325,255 \\
\hline & R6 & 22502,088 & 782,258 & 20950,111 & 24054,066 \\
\hline & R7 & 13805,064 & 538,464 & 12736,767 & 14873,361 \\
\hline & R8 & 5658,932 & 242,629 & 5177,563 & 6140,300 \\
\hline \multirow[t]{9}{*}{ Fixation Count (FC) } & RO & 21,537 & 1,319 & 18,920 & 24,154 \\
\hline & $\mathrm{R} 1$ & 33,043 & 1,276 & 30,511 & 35,575 \\
\hline & $\mathrm{R} 2$ & 45,579 & 2,357 & 40,902 & 50,255 \\
\hline & R3 & 19,797 & 1,176 & 17,464 & 22,129 \\
\hline & R4 & 12,952 & 1,601 & 9,776 & 16,127 \\
\hline & R5 & 7,005 & ,786 & 5,445 & 8,566 \\
\hline & R6 & 83,004 & 2,694 & 77,658 & 88,349 \\
\hline & R7 & 53,091 & 1,944 & 49,234 & 56,949 \\
\hline & R8 & 22,967 & ,944 & 21,095 & 24,839 \\
\hline \multirow[t]{9}{*}{ Revisits (RV) } & RO & 4,350 & 202 & 3,950 & 4,750 \\
\hline & $\mathrm{R} 1$ & 5,019 & 236 & 4,551 & 5,486 \\
\hline & $\mathrm{R} 2$ & 7,396 & 317 & 6,768 & 8,025 \\
\hline & R3 & 4,012 & 211 & 3,594 & 4,429 \\
\hline & R4 & 1,421 & 157 & 1,109 & 1,733 \\
\hline & R5 & 1,135 & 138 & ,861 & 1,410 \\
\hline & R6 & 10,935 & ,445 & 10,053 & 11,817 \\
\hline & R7 & 10,477 & 397 & 9,689 & 11,266 \\
\hline & R8 & 3,894 & 172 & 3,553 & 4,236 \\
\hline
\end{tabular}


Table A6

Test of within-subjects contrasts of dwell times.

Tests of Within-Subjects Contrasts

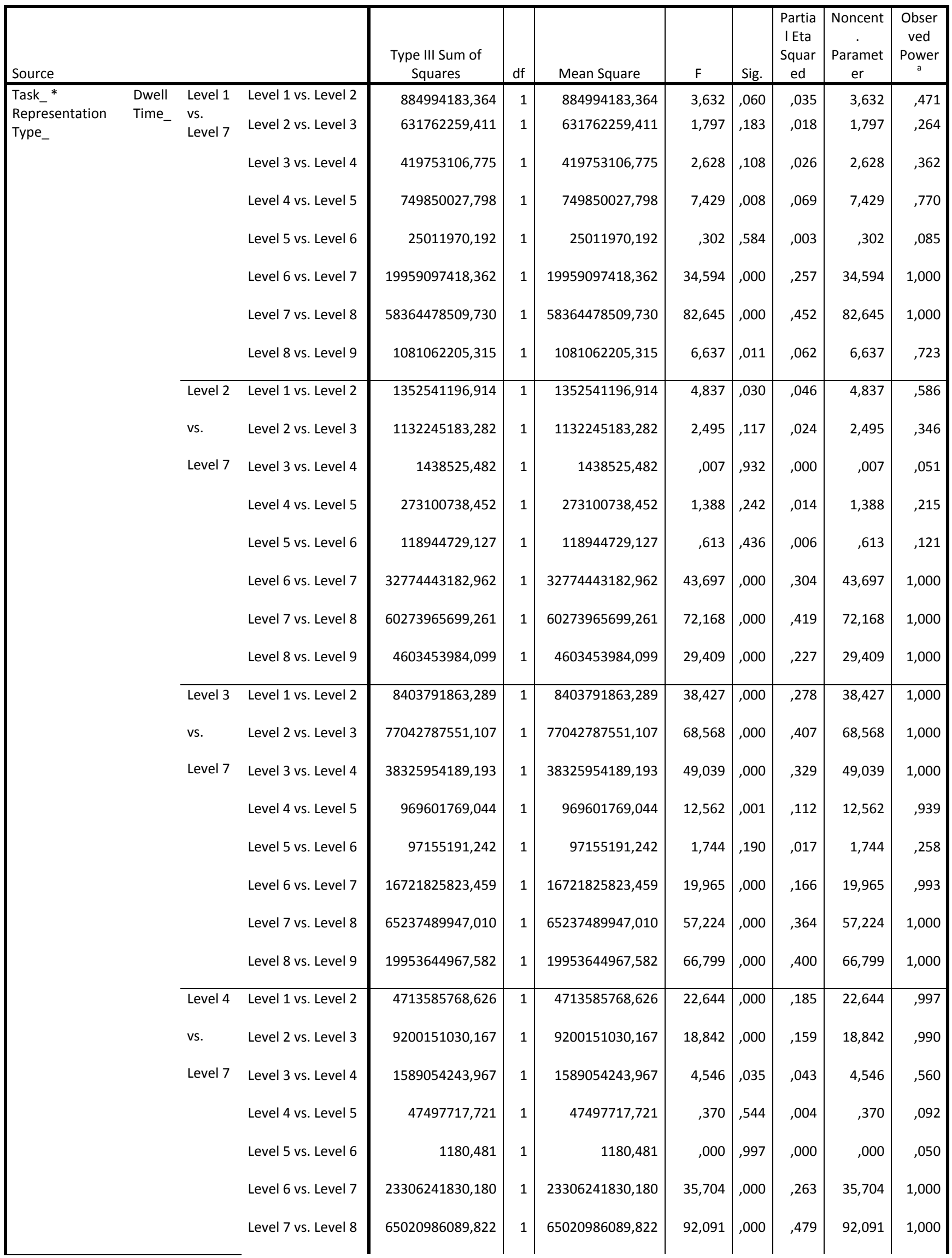




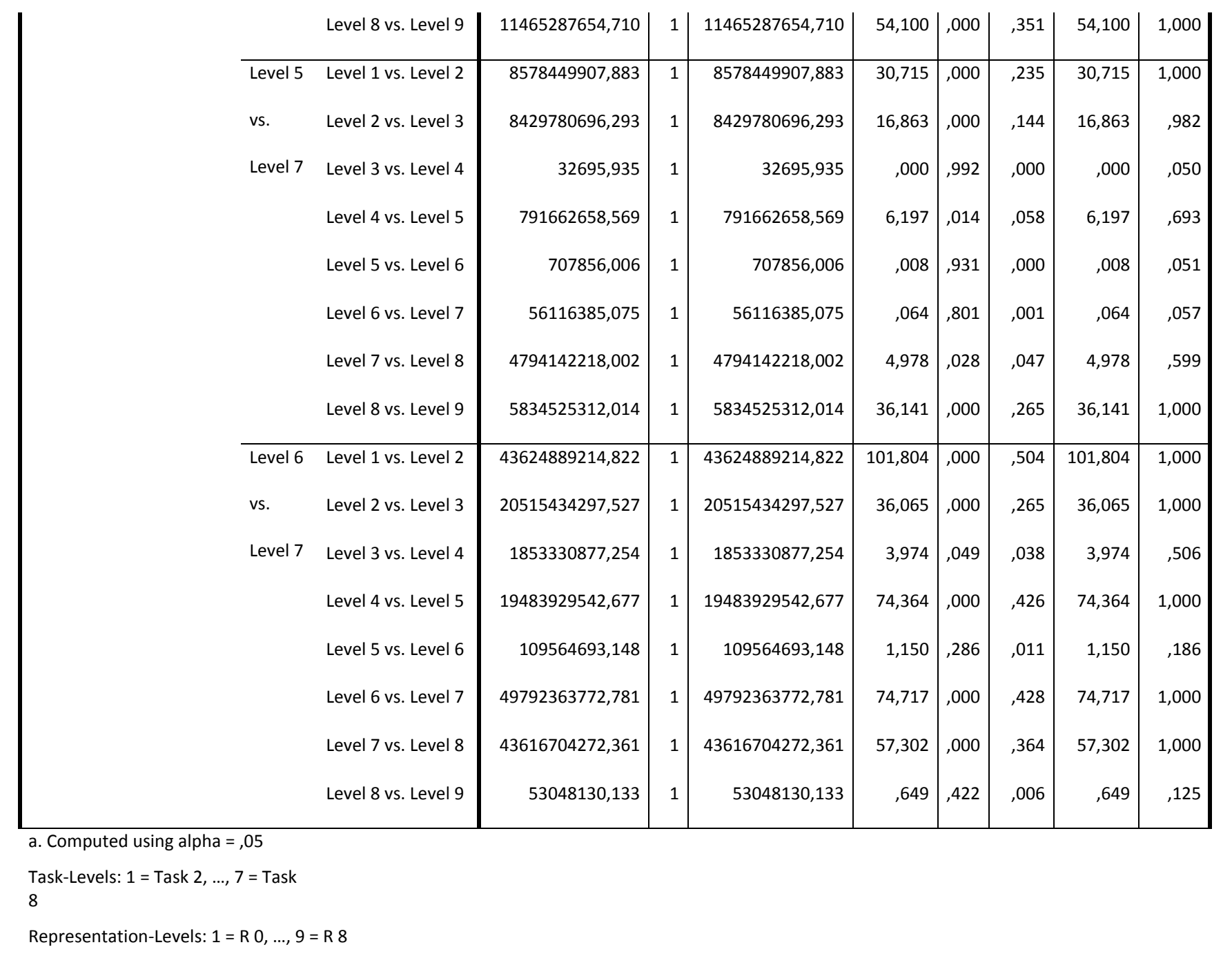

